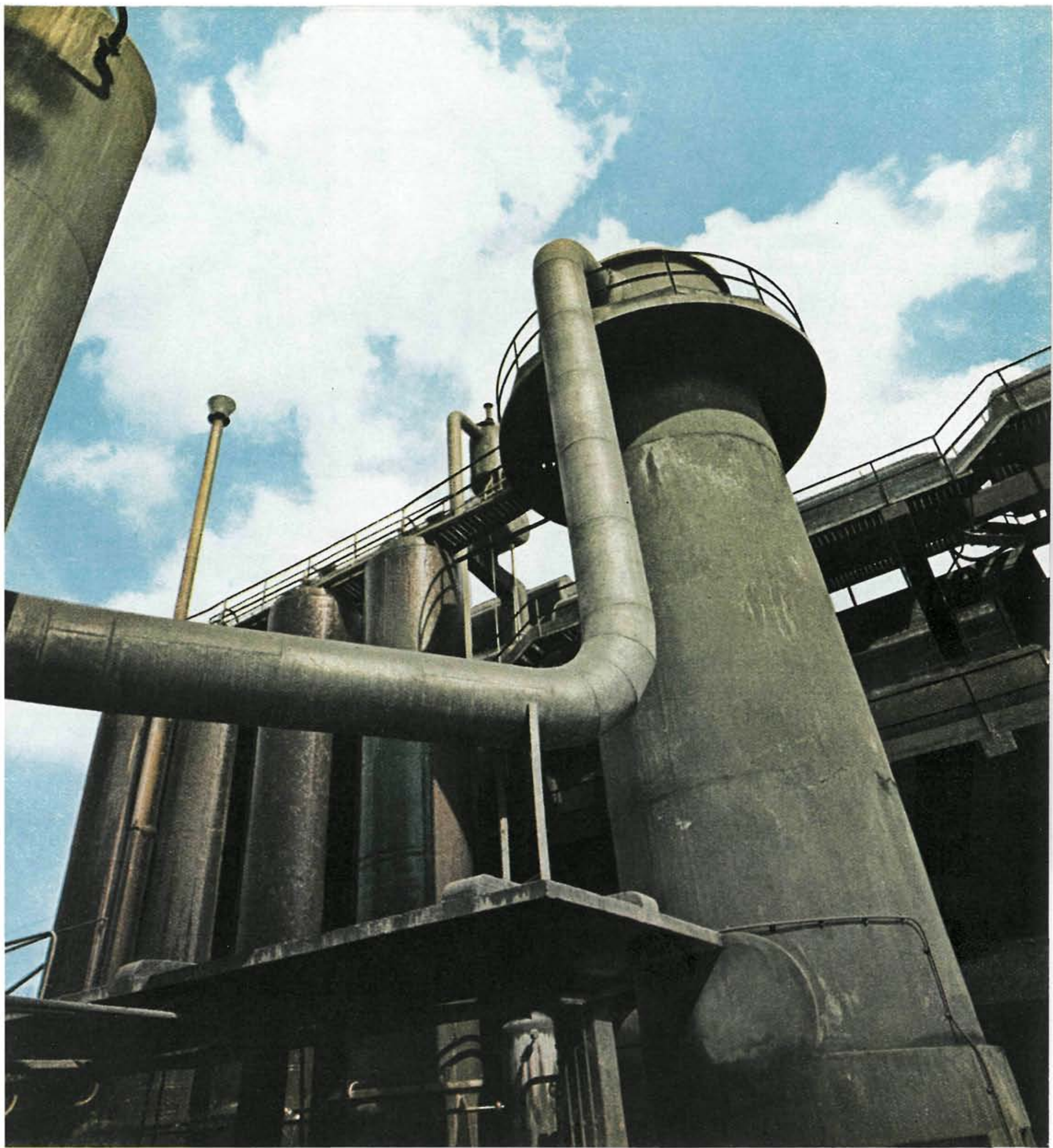

\title{
la factoría de Barros (La Felguera) de la sociedad ibérica del nitrógeno
}

C. FERNANDEZ CASADO, ingeniero de caminos 


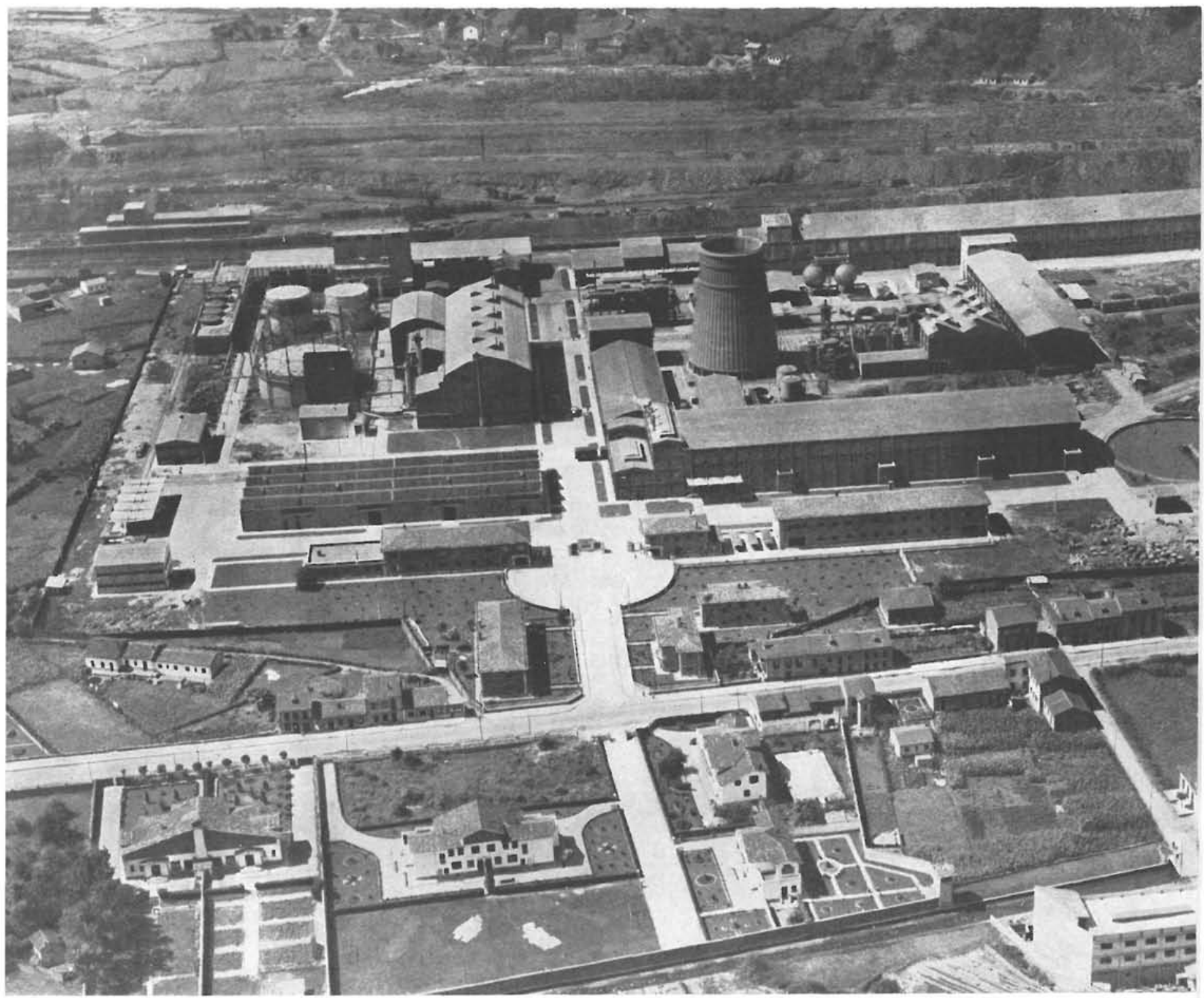

\section{Disposición general}

La Sociedad Ibérica del Nitrógeno inició sus instalaciones de La Felguera en el año 1923, utilizando un terreno delímitado por la línea del ferrocarril, la factoría de Duro Felguera y las explotaciones mineras inmediatas. Al agotar las posibilidades de este solar, por sucesivas ampliaciones, decidió trasladarse a una zona despejada, fuera de la aglomeración urbana e industrial, donde poder desarrollar sin trabas una nueva factoría más importante que la primitiva.

En esta nueva factoría de Barros, el terreno queda delimitado únicamente en dos de sus lados opuestos por las lineas casi paralelas del ferrocarril y de la carretera, que le proporcionan unas condiciones óptimas para entrada de materias primas y salida de productos.

En el plano de la figura 2, aparece la planta de sus distintas edificaciones, indicando las construídas ya y Ias que se amplian en la actualidad. Como puede verse, la distribución se ha realizado con perfecta regularidad, completándose con una urbanización amplia y lujosa, gracias a las zonas verdes que las condiciones climatológicas permiten mantener sin gran esfuerzo.

Esta distribución se planeó por los ingenieros de S. I. N., quienes definieron, además, los edificios en sus líneas esenciales, de acuerdo con las instalaciones de maquinaria, procedentes de fábricas francesas, inglesas y alemanas. A nosotros nos ha correspondido exclusivamente el proyecto de todos los edificios industriales, partiendo de los datos que acabamos de indicar, los cuales definian las dimensiones principales en plantas y alzados, asi como las funciones especíticas, cargas estáticas y dinámicas que habían de tenerse en cuenta.

La planta de la instalación indica ya la diversidad de las construcciones, con dimensiones y formas tan diferentes por corresponder a fines tan variados como: naves de fabricación, almacenes, talleres, parques de materias primas. soportes de depósitos de líquidos o gases, etc, 


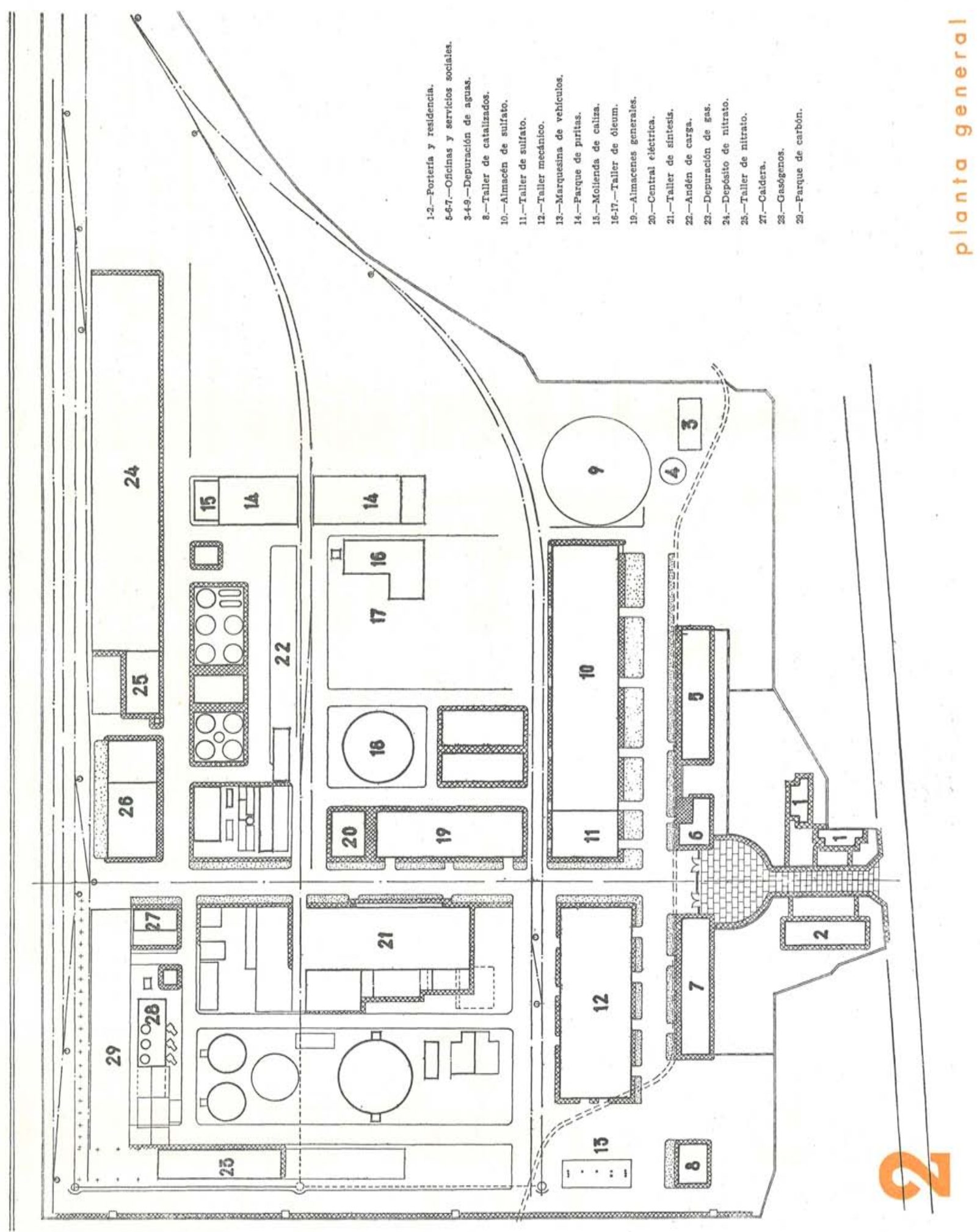



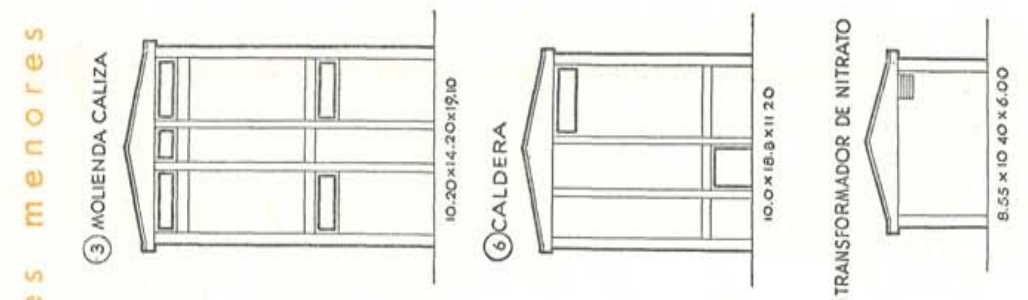

๑)
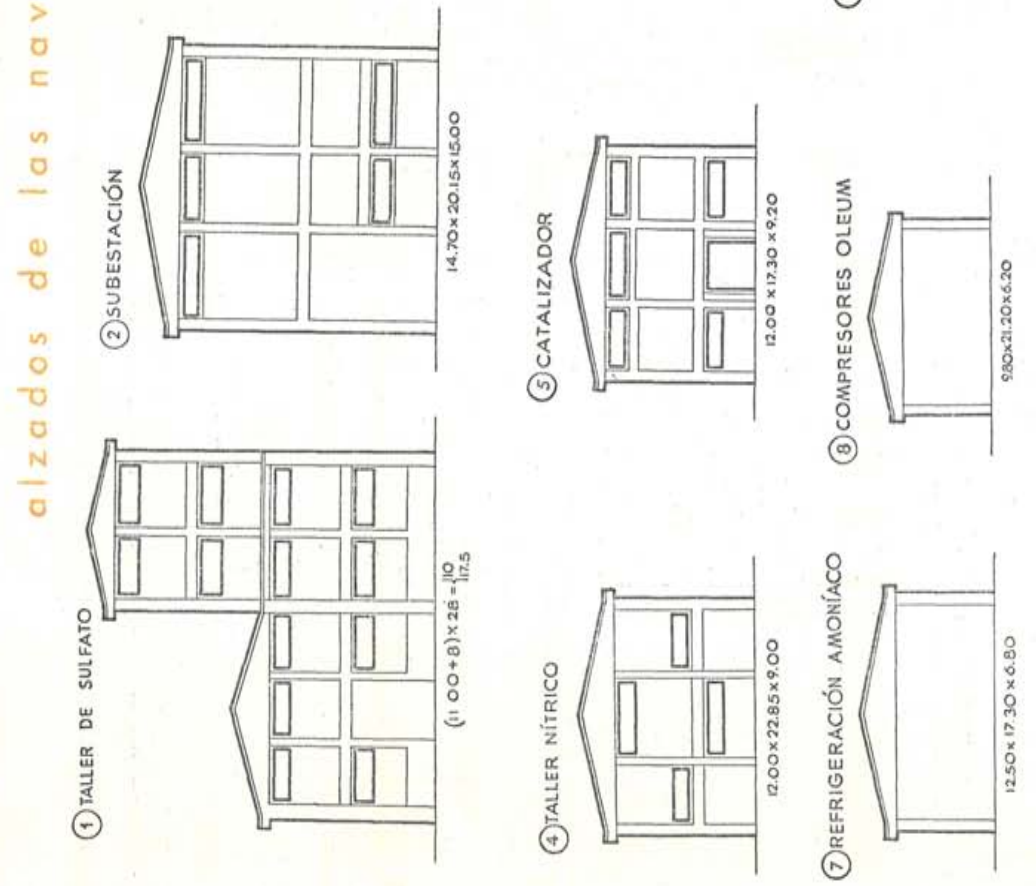

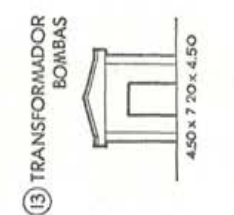

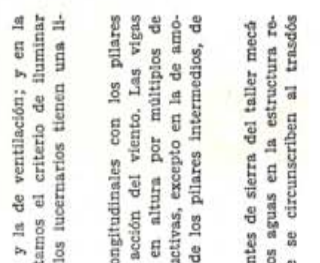
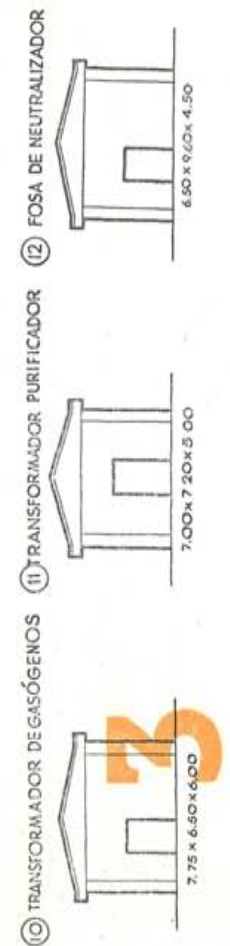

势

政

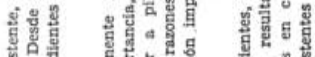

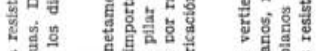

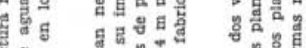

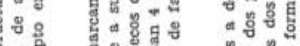

ช.

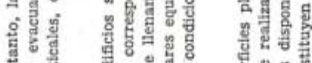

oำ

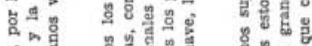

害器

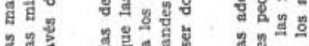

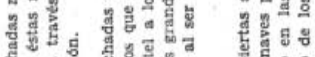

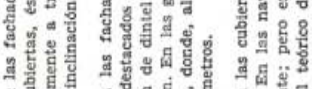

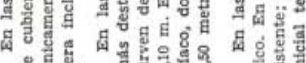

(2)

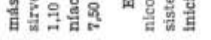
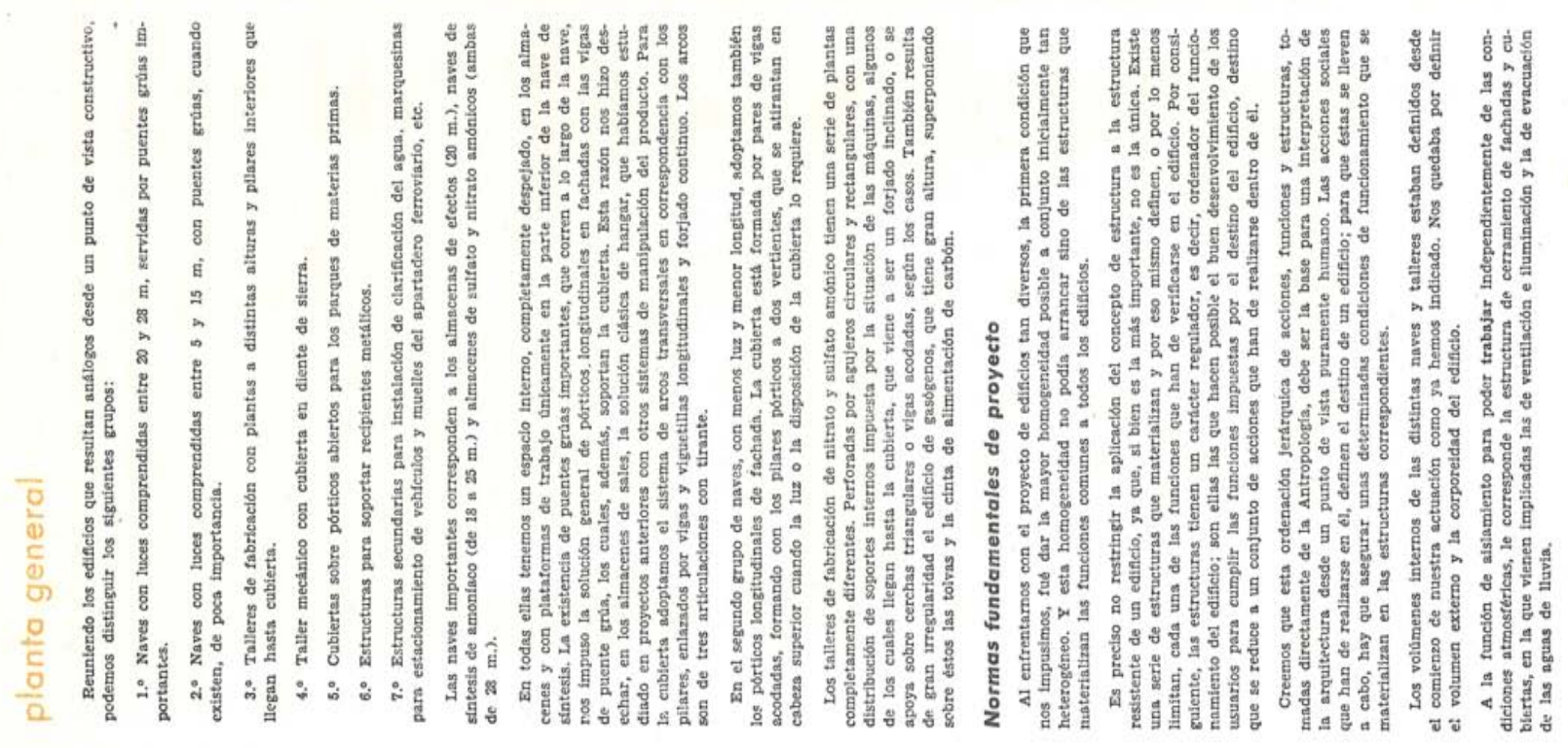
La ventilación se ha dispuesto en la coronación de las cubiertas, normalmente mediante linternón corrido abierto libremente o protegido con persianas cortalluvias y viseras horizontales, Donde la ventilación ha de ser más intensa-naves de sintesis y de fabricación de ácico sulfúrico-prolongamos los planos terminales de cubierta alternando de lado en cada paño, hasta dejar amplia abertura vertícal entre dicho plano y el de la vertiente contraria.

Para relacionar entre sí todas las cubiertas hemos adoptado dos inclinaciones tipo: la de 1 a 4 , en los planos simétricos de las dos vertientes de las naves menores, y en los planos de cubrera de las naves de mayor luz. La otra pendiente de 1 a 2 corresponde a los faldones inferiores de estas naves, y la hemos adoptado también en la cubierta de las de Oleum, donde se precisaba una ventilación enérgica para evacuación de gases.

La estructura de evacuación de aguas se completa cubriendo las superficies inclinadas de hormigón, con teja plana y recogiendo aguas a los bordes de cubierta en vigas canalón, desde las que descienden al alcantarillado por bajantes de uralita que en la última zona se convierten en tubos de fundición. En el caso de la nave de sintesis donde pueden producirse explosiones por formarse atmósfera inflamable, se ha reducido al mínimo la importancia de la cubierta, suprimiéndose el forjado de continuidad y cerrando mediante uralita directamente apoyada sobre las viguetas que enlazan los arcos.

Toda la carpintería de ventanales es de hormigón armado, excepto en los lucernarios de los dientes de sierra, que es metálica con un cierto número de recuadros practicables para ventilación natural.

\section{Proceso constructivo}

Otra de las relaciones de homogeneidad entre los edificios ha derivado del proceso constructivo, que ha sido de premoldeo en todas las cubiertas con luz superior a $15 \mathrm{~m}$. Arcos o cerchas con sus vigas de arriostramiento y viguetas se construyeron en el suelo agrupadas para economizar moldes y en lugares muy próximos a los de utilización definitiva, Los arcos, como se ve en la figura 4, se construyeron en bloques verticales utilizando un encofrado inferior común con superficie siguiendo la forma del intradós. Las cerchas para los parques cubiertos de carbón y de caliza y para las naves de Oleum, se moldearon horizontalmente en grupos de dos (fig. 5).

En proyecto se daba una solución también premoldeada para la superficie de cierre de cubierta con viguetillas y placas de hormigón celular, pero se había previsto, además, reducir el premoldeo a arcos y vigas riostras ejecutando un forjado cerámico in situ. Por este motivo se adoptó la separación entre arcos de 4 metros, lo que permitió realizar el encofrado simplemente sobre tablones normales apoyados en otros que se adosaban a las caras laterales de los arcos antes de elevarlos (fig. 6).
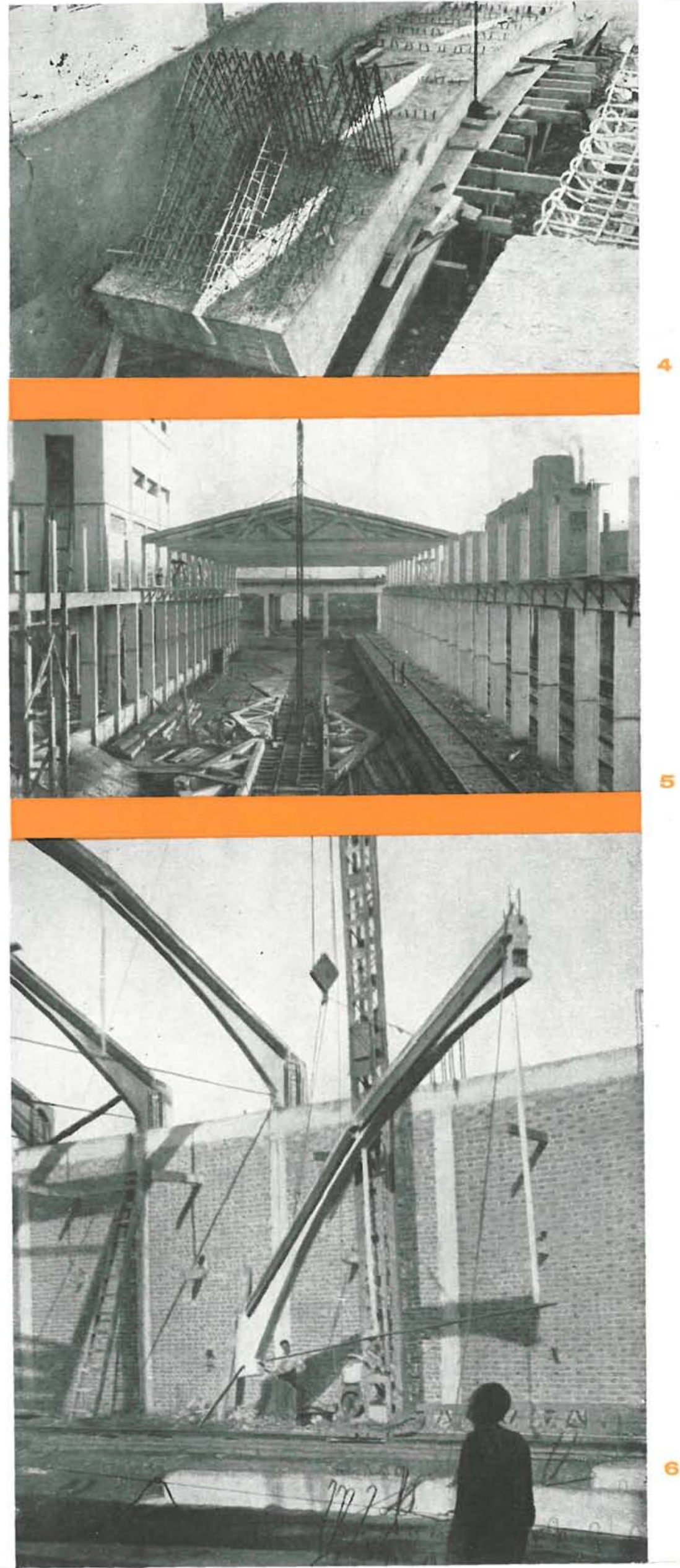


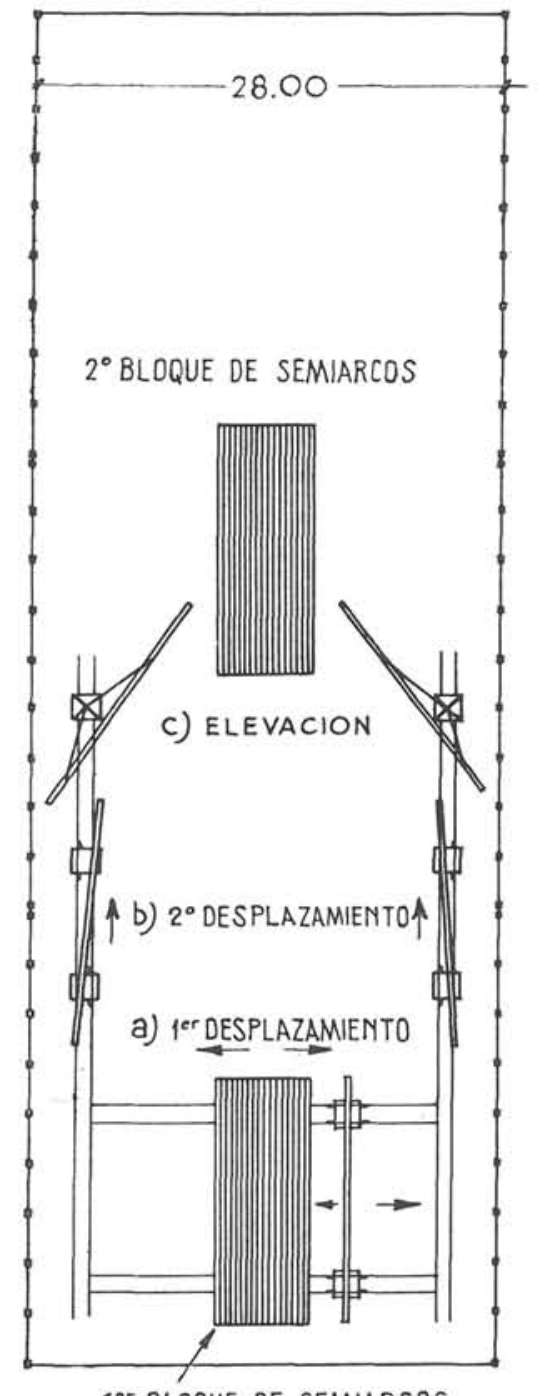

1er BLDQUE DE SEMIARCOS

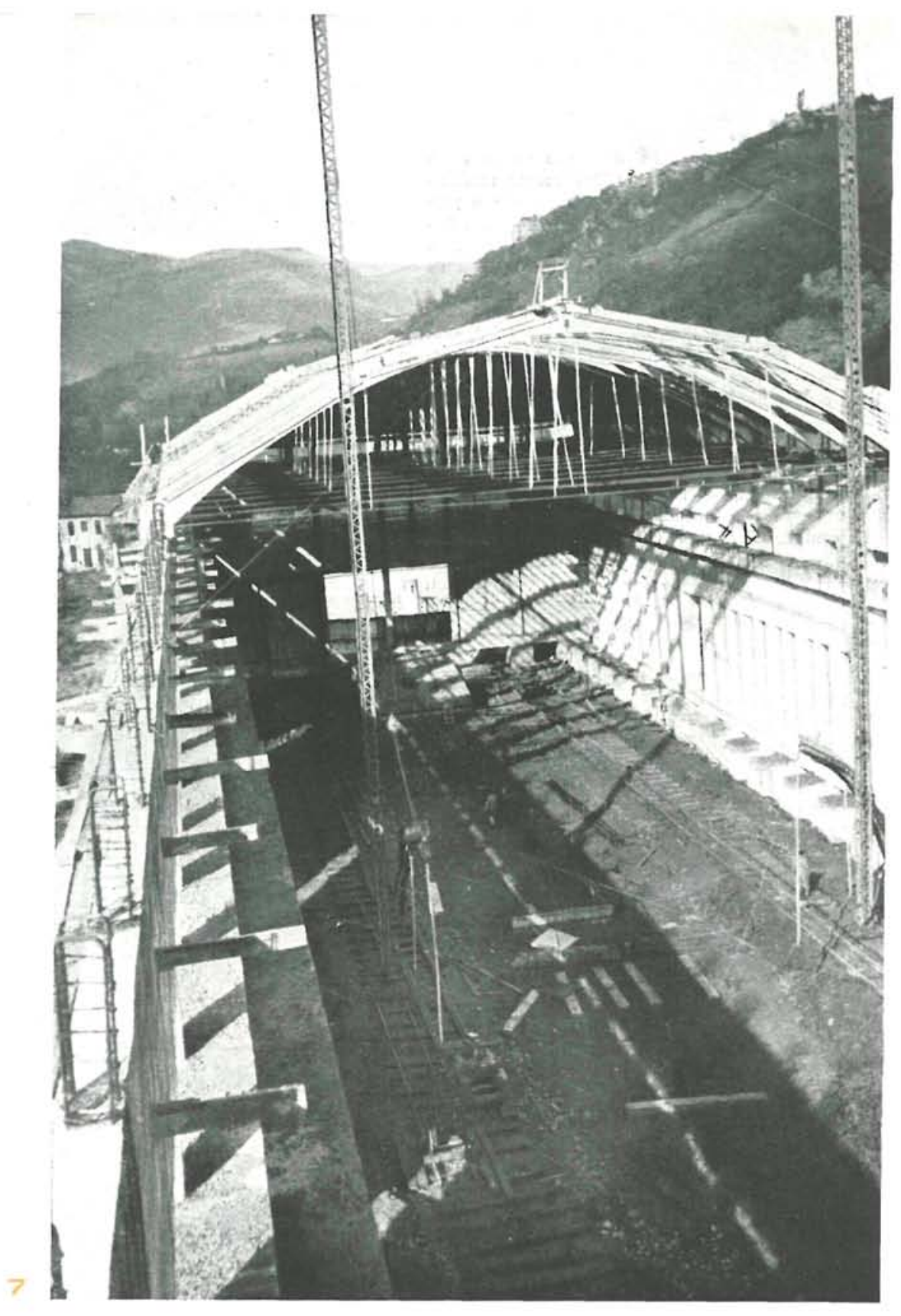

En las naves de sintesis, asi como en las cubiertas de los parques de materiales, se empleó el premoldeo total, pues el cubrimiento se ha realizado apoyando la uralita directamente sobre vigas riostras $\mathrm{y}$ viguetas.

La elevación de $\operatorname{arcos} \mathrm{y}$ cerchas se llevó a cabo mediante plumas metálicas. En las naves grandes se utilizaron dos de $30 \mathrm{~m}$ de altura, una por cada semiarco (fig, 7), ya que, aprovechando la division natural correspondiente a la articulación de clave, la unidad de manejo era el medio arco con un peso máximo de 9 toneladas en los almacenes de nitrato y sulfato.

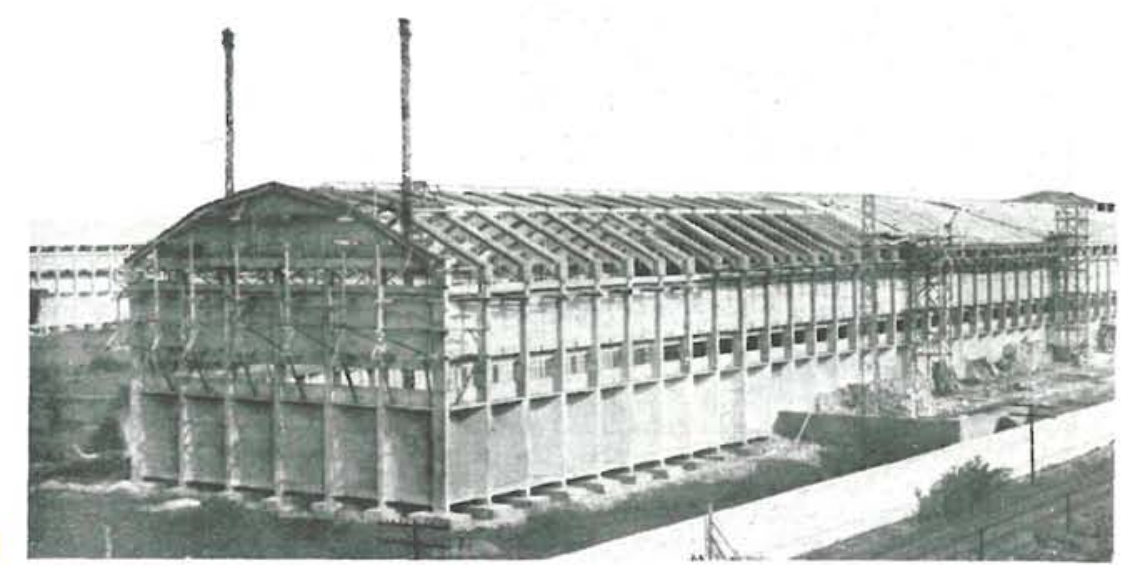




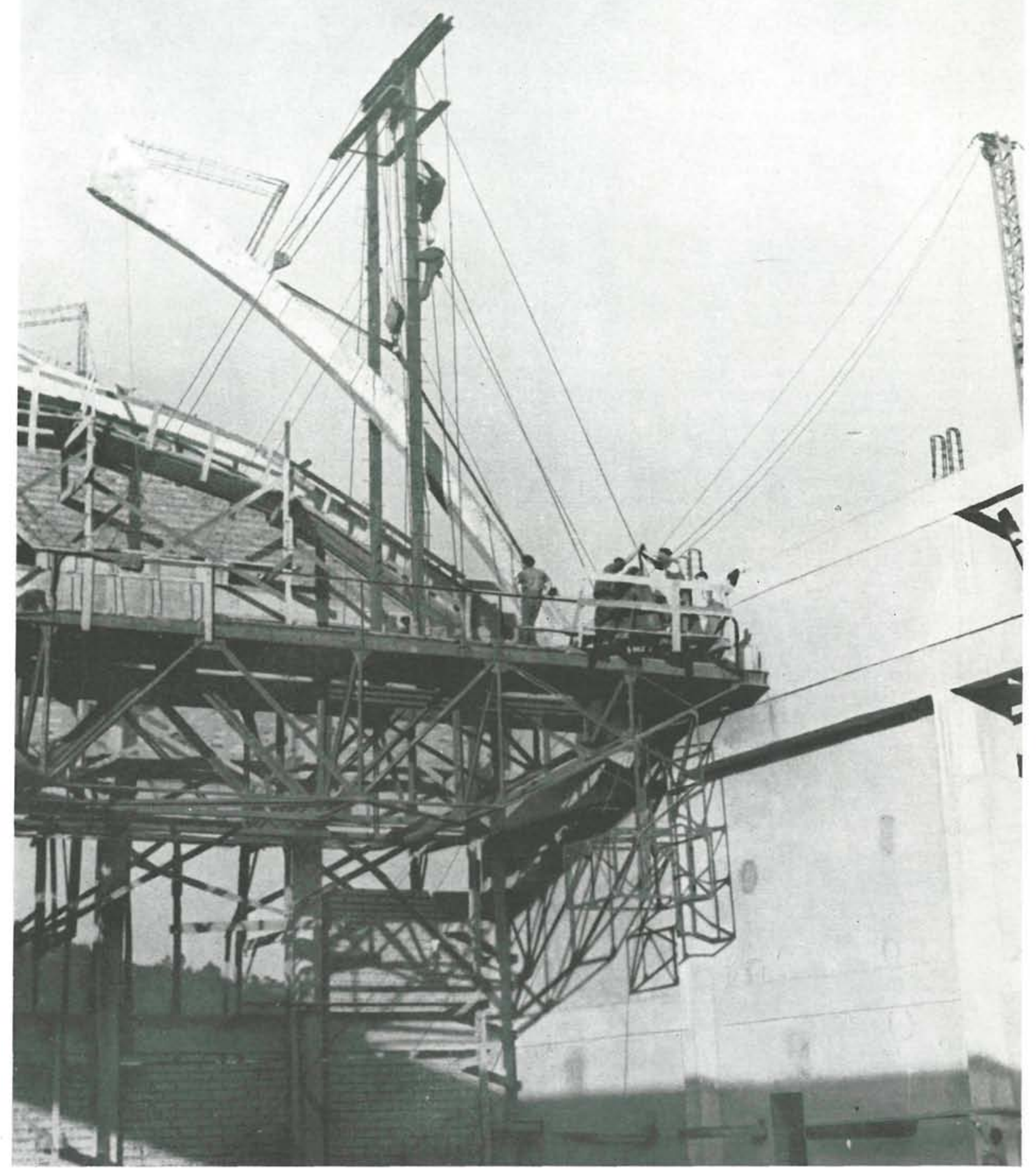

En la nave principal de sintesis se utilizó el puente grúa definitivo, montado inmediatamente después de construir los pórticos laterales, recogiendo los dos semiarcos en ambas extremidades y llevándolos izados hasta su posición definitiva donde se abatieron (fig. 9).

En las cerchas del taller mecánico, construídas horizontalmente en bloques correspondientes a todos los elementos de una crujia, y en la extremidad de ella, se transportaron mediante un carretón de madera rodando directamente sobre las vigas de los pórticos. 


\section{Naves principales}

La disposición típica de la estructura transversal de una nave es la de las figuras 11 y 12 , que corresponde al depósito de sulfato amónico. La cimentación se ha realizado empotrando los pilares en bloques paralelepipédicos de hormigón en masa. Los pilares tienen sección rectangular, que arranca de $100 \times 40 \mathrm{y}$ se reduce a $55 \times 40$ al pasar de la viga de puente grúa. Están arriostrados en pies y cabezas por sendas vigas riostras, sirviendo a este mismo fin la de puente grúa en el intermedio. Los arcos, con una anchura constante de $25 \mathrm{~cm}$, tienen canto variable, siguiendo el intradós una curva parabólica y el trasdós los cuatro segmentos rectos de las vertientes, conservando un canto minimo de $50 \mathrm{~cm}$.

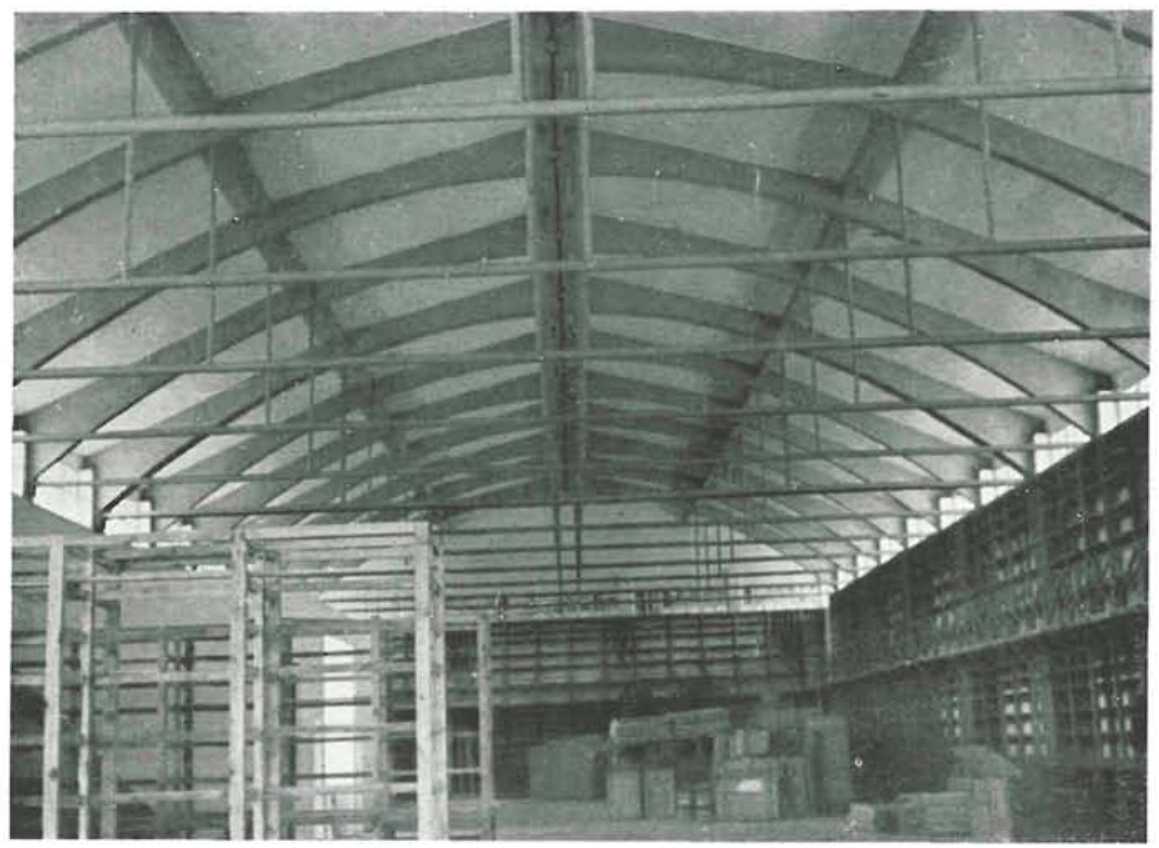

10

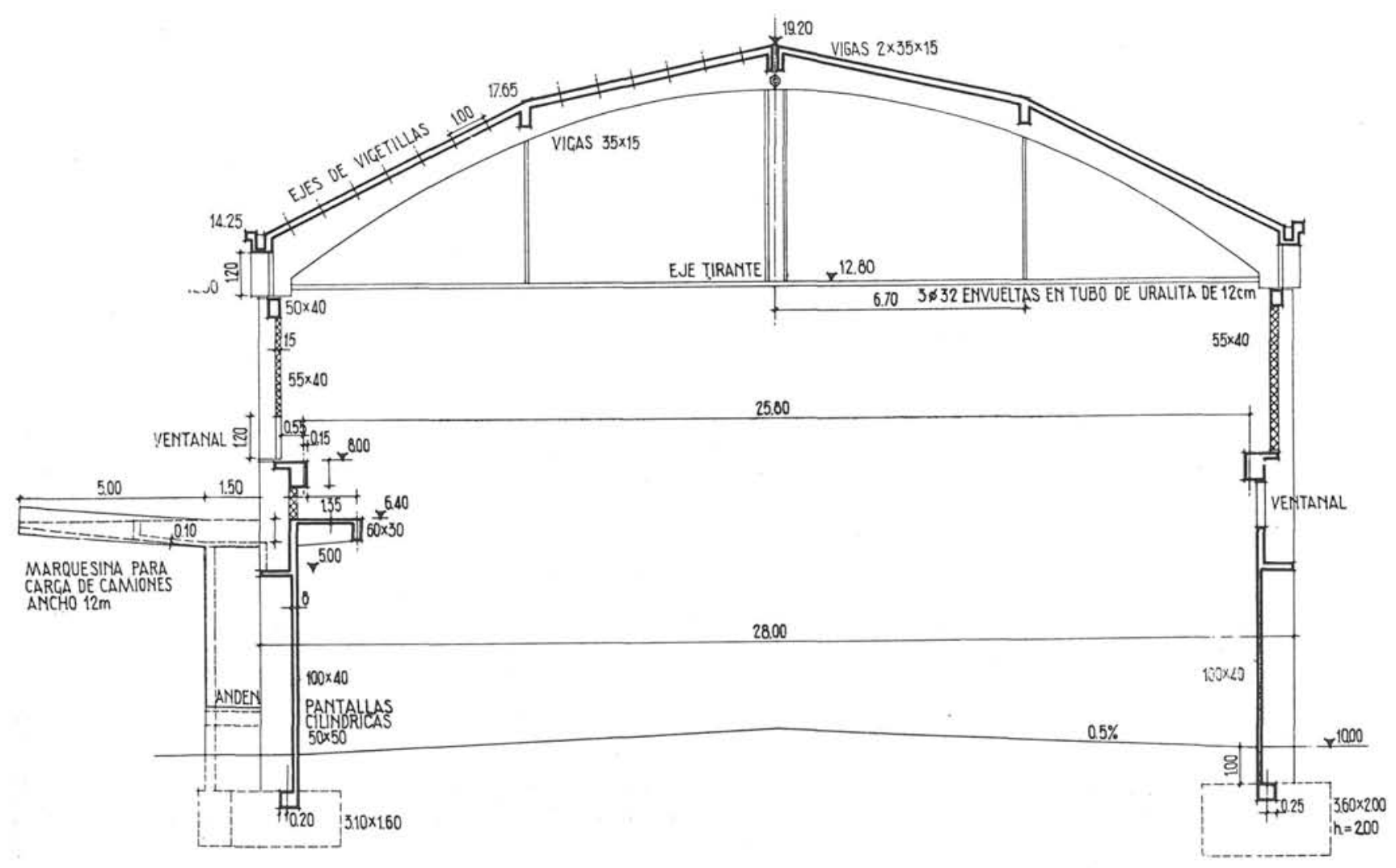




\section{alzado y planta}

Los apoyos sobre los pilares se hacen en una primera etapa sobre placa de plomo y definitivamente a través de un pasador $(\varnothing / 40)$, que atraviesa la cabeza del arco y queda embebido en orejas laterales solidarias de la viga de coronación. Tenemos así verdadera articulación de giro, y para conseguir en una de las extremidades la articulación de desplazarniento horizontal convertimos en péndulo el trozo de pilar por encima de la viga de puente grúa, articulando en la sección inferior con hierros pasantes verticales. La articulación de clave se obtiene mediante rodillo de acero entre placas del mismo material. (En las realizaciones de naves actuales, la articulación de clave es provisional y la suprimimos después de construída toda la cubierta.)

El tirante está formado por redondos de $30635 \mathrm{~mm}$ con extremidades ancladas en placas metálicas embebidas en el hormigón.

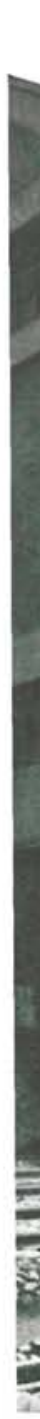
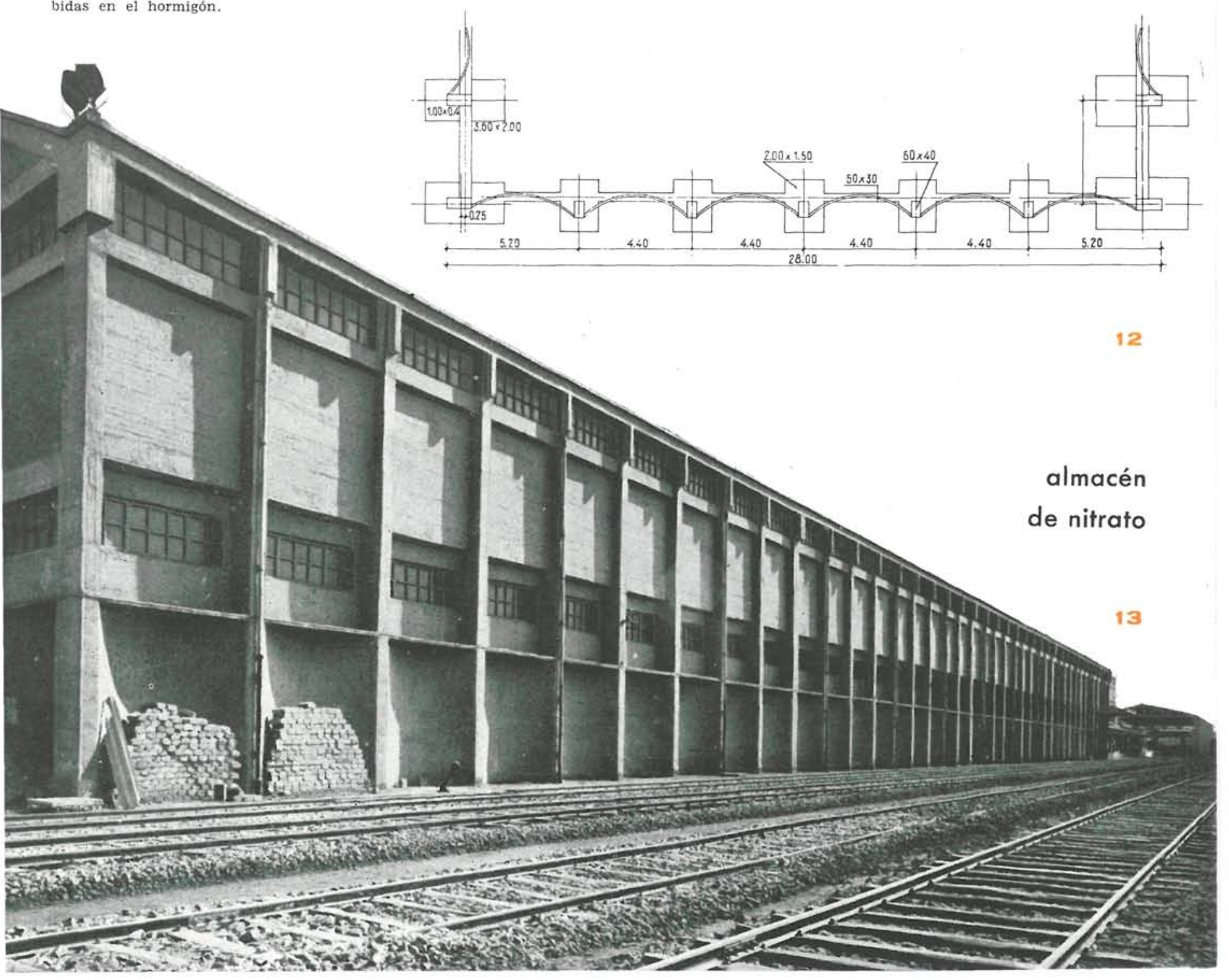

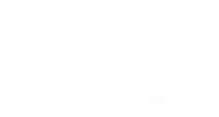

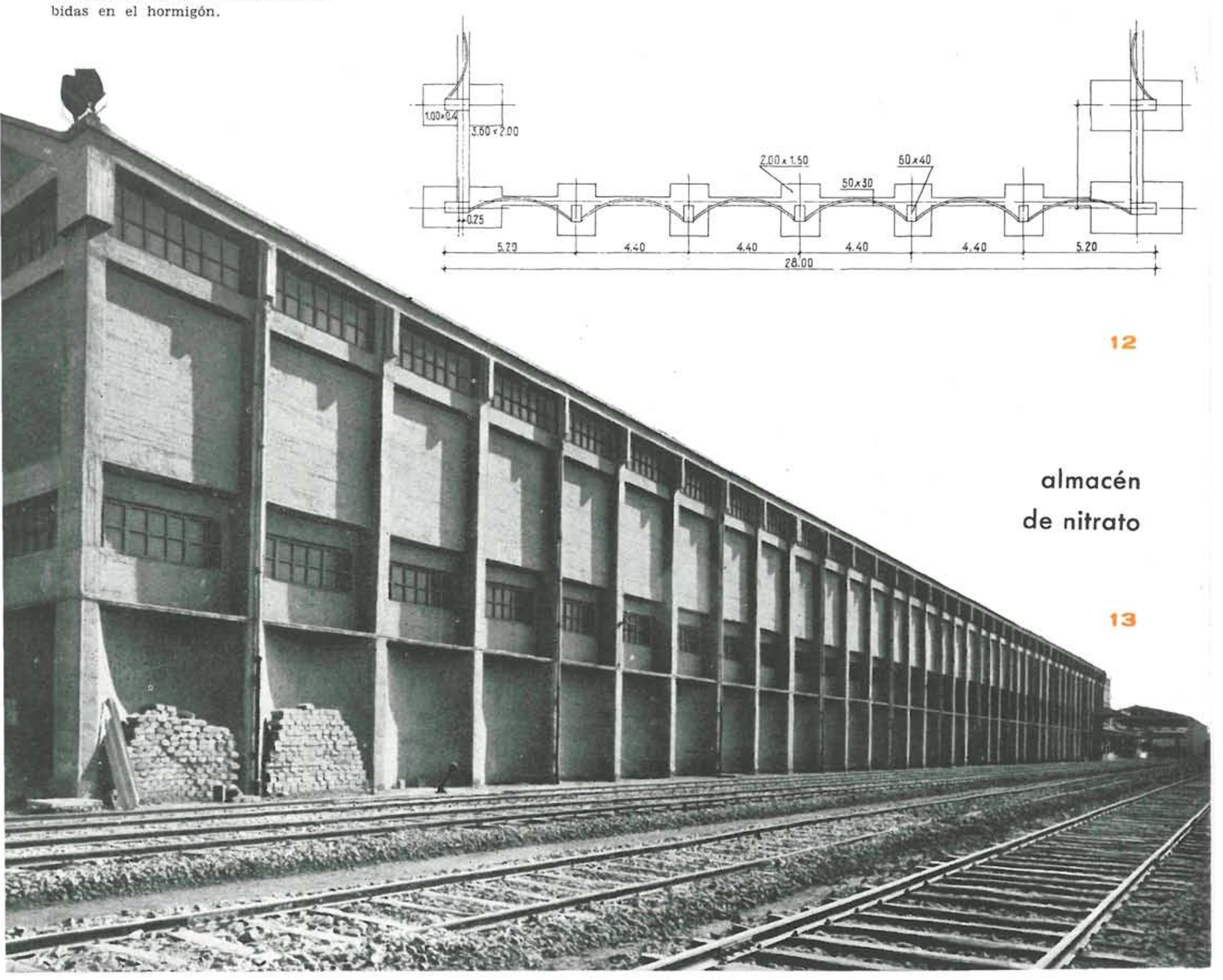

12
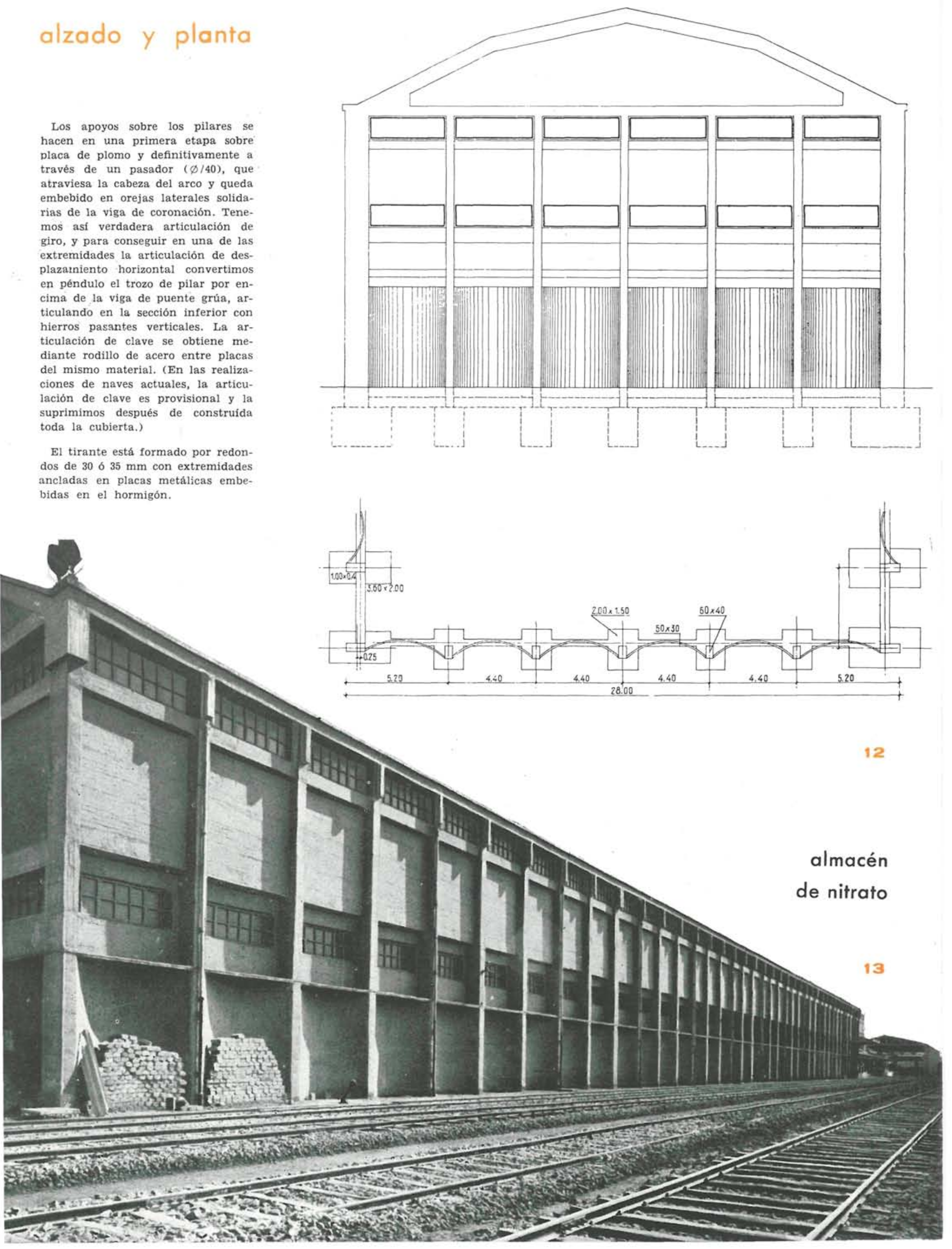

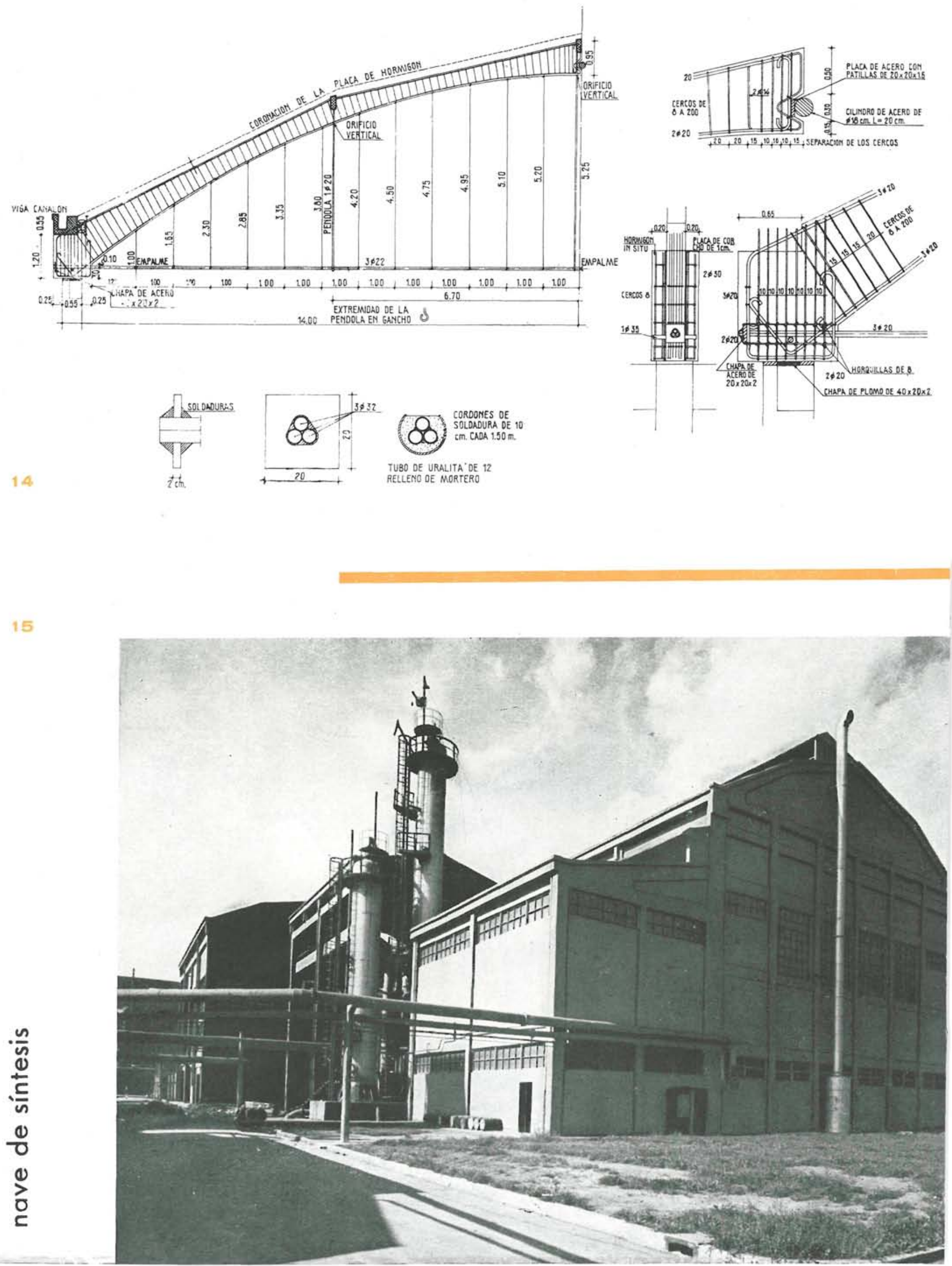


\section{plataforma de maniobra}

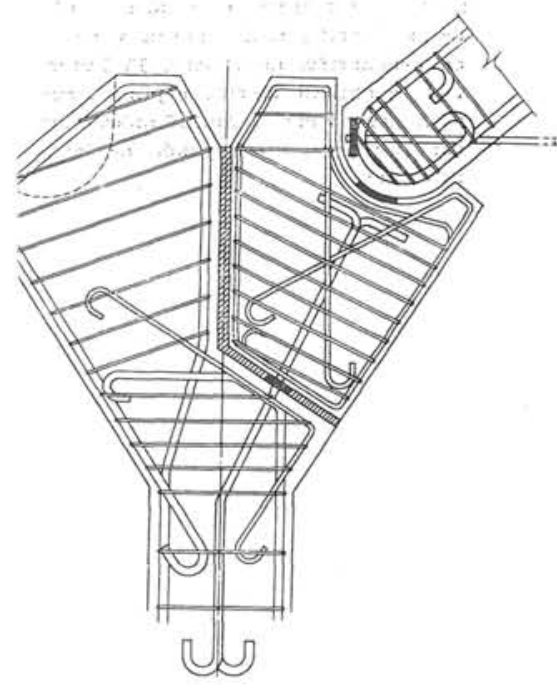

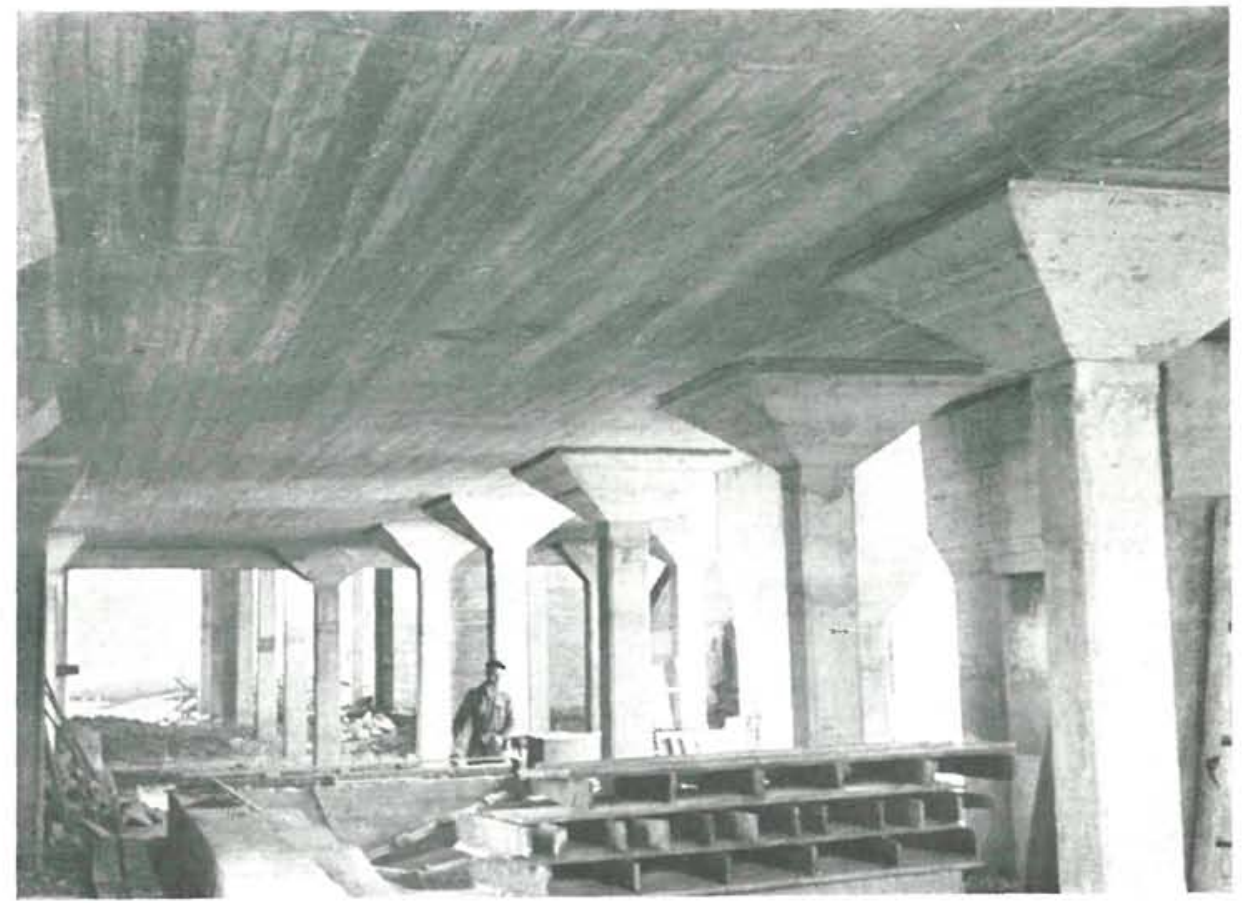

16

\section{detalle de nudo central}

Las barras se empalmaron por soldadura, y el último empalme se hizo en obra al cerrar los semiarcos. Para proteger los tirantes y péndulas de la oxidación se embebieron todos los redondos en hormigón al final de la obra, utilizando tubos de uralita que sirvieron de encofrado y dan un agradable aspecto final.
En el taller de sintesis, que tiene dos naves adosadas, hemos utilizado un sistema de sustentación de arcos mediante vigas bielas que facilitan el apoyo de los dos contiguos sobre un mismo pilar, y permiten, además, reducir la sección del tirante al trasladar a pilares una parte del empuje de los arcos (fig. 17).

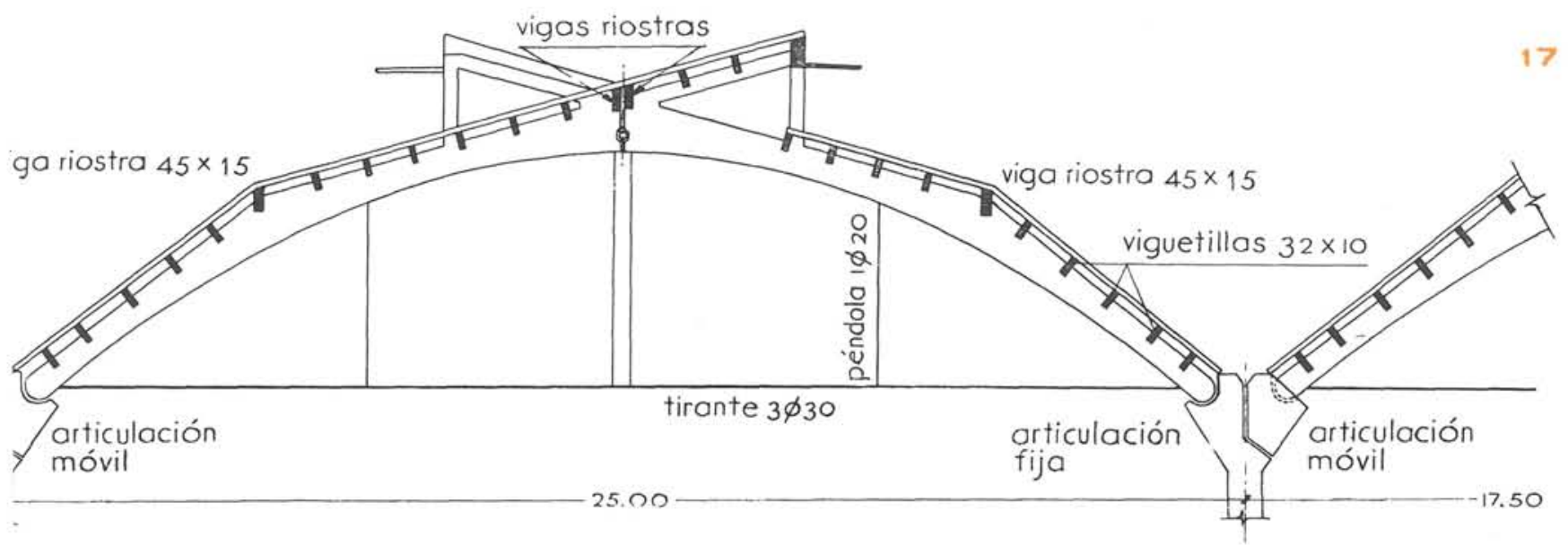




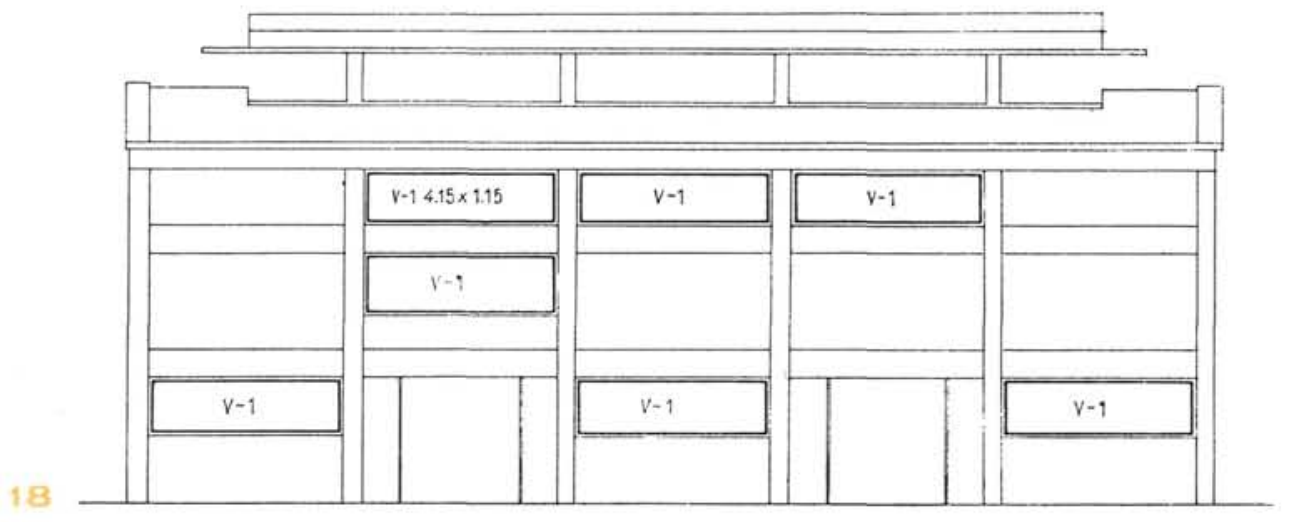

\section{Naves menores}

En las naves menores la sección transversal típica es la de las figuras 19 y 20 , que corresponde al taller de nítrico, con $12 \mathrm{~m}$ de luz. Los pilares de $65 \times 35$ se retranquean a $30 \times 35$ al rebasar las vigas de puente grúa y se enlazan en cabeza mediante viga solidaria con forma especial derivada de la función sustentadora y de la de evacuación de lluvias. El linternón se obtiene mediante pilares que sostienen vigas longitudinales, las cuales soportan el forjado de losas acodadas.
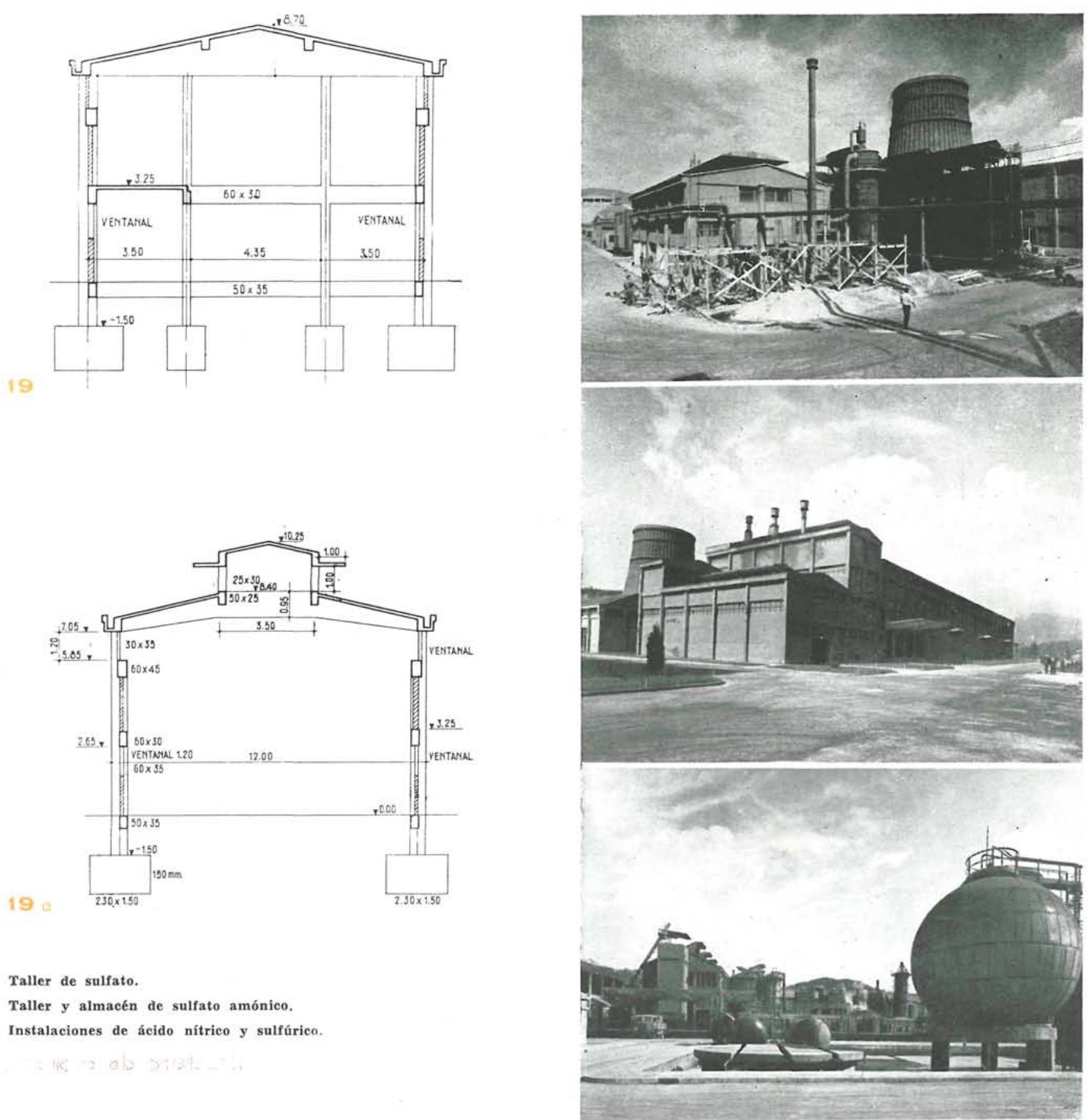

Taller de sulfato.

Taller y almacén de sulfato amónico.

Instalaciones de ácido nítrico y sulfúrico. 
taller de sulfato

\section{secciones tipo}

En otras naves que no tienen linternón, la cubierta está formada por simples vigas acodadas de sección constante, atirantadas para absorber el empuje del efecto arco correspondiente. Las vigas de coronación de los entramados longitudinales de las naves son vigas canalón, iguales en todas, que rebasan la superficie de fachada formando un simple remate.

En los testeros se acusan vigas obtenidas al revolver las de los entramados longitudinales, combinadas con pilares para formar el entramado que resiste la acción del viento. En todas las naves coronamos estas fachadas con simple frontón definido por los planos de las vertientes (pendiente 1 a 4) y el inferior horizontal del canalón.

\section{Planos de cerchas}

Tenemos tres naves cubiertas con cerchas (fig. 21): las de ácido sulfúrico (Oleum), especiales por su fuerte pendiente y la prolongación en cuernos para la ventilación (figura 23): las de los parques de material con pequeño declive, $y$ las del taller de nitrato, cuya fuerte pendiente viene obligada al adosarse su testero a la zona lateral del almacén de nitrato.
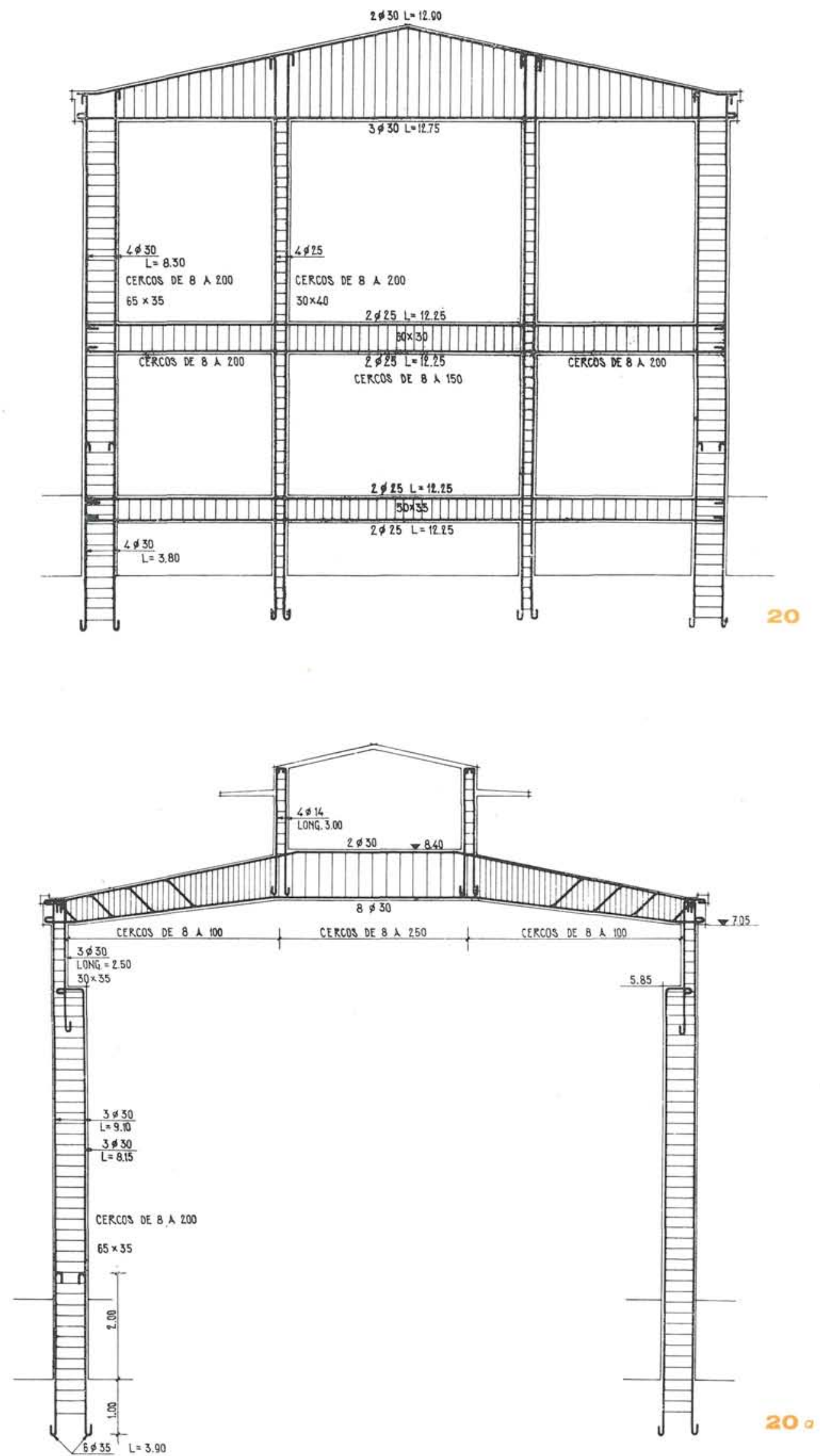
\begin{tabular}{l}
0 \\
0 \\
$\frac{0}{u}$ \\
0 \\
0 \\
0 \\
0 \\
0 \\
$\frac{1}{0}$ \\
\hline 2
\end{tabular}

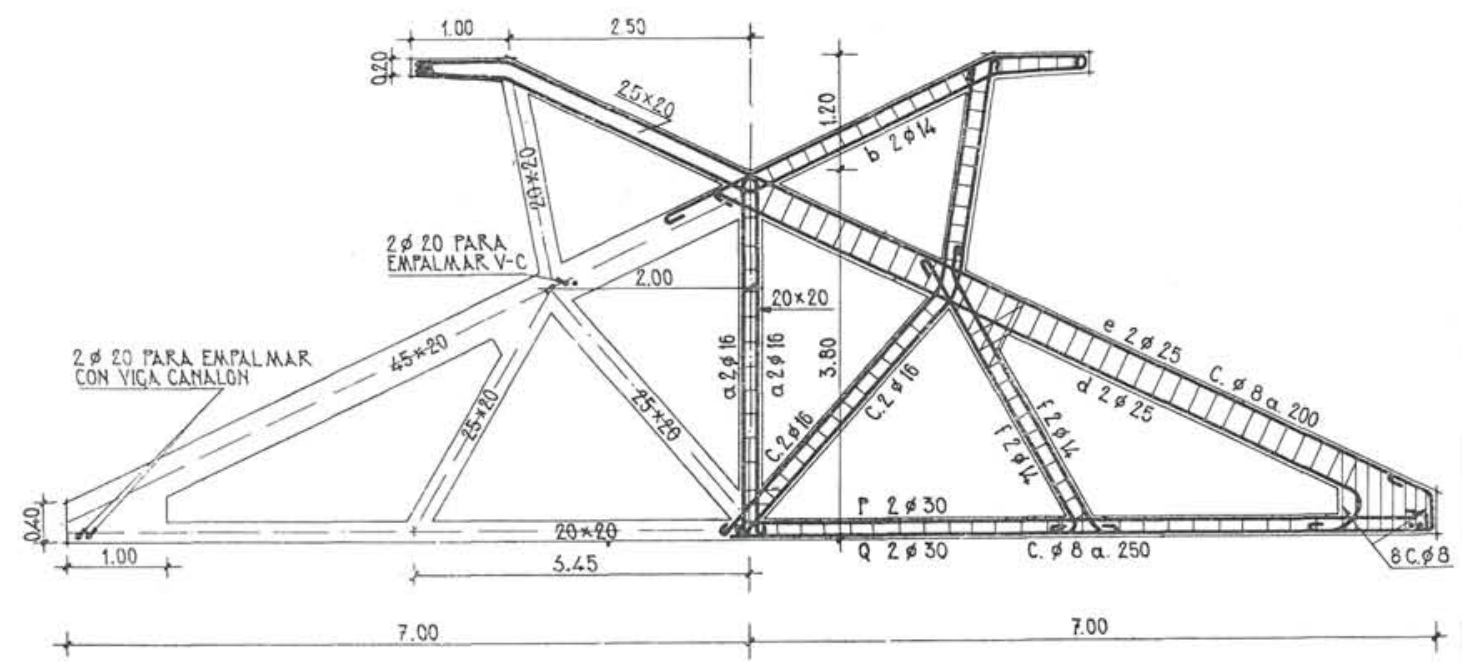

21 a
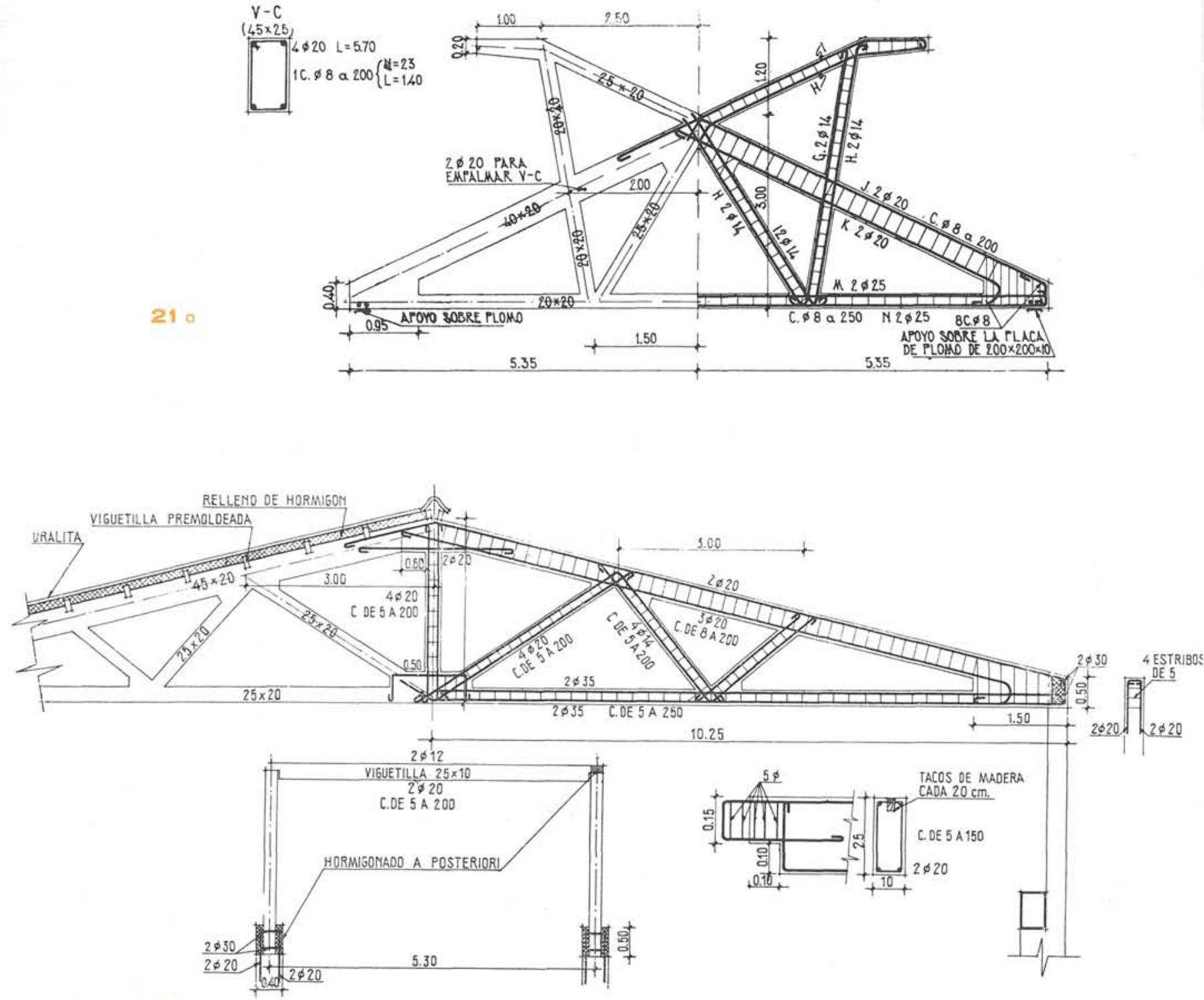


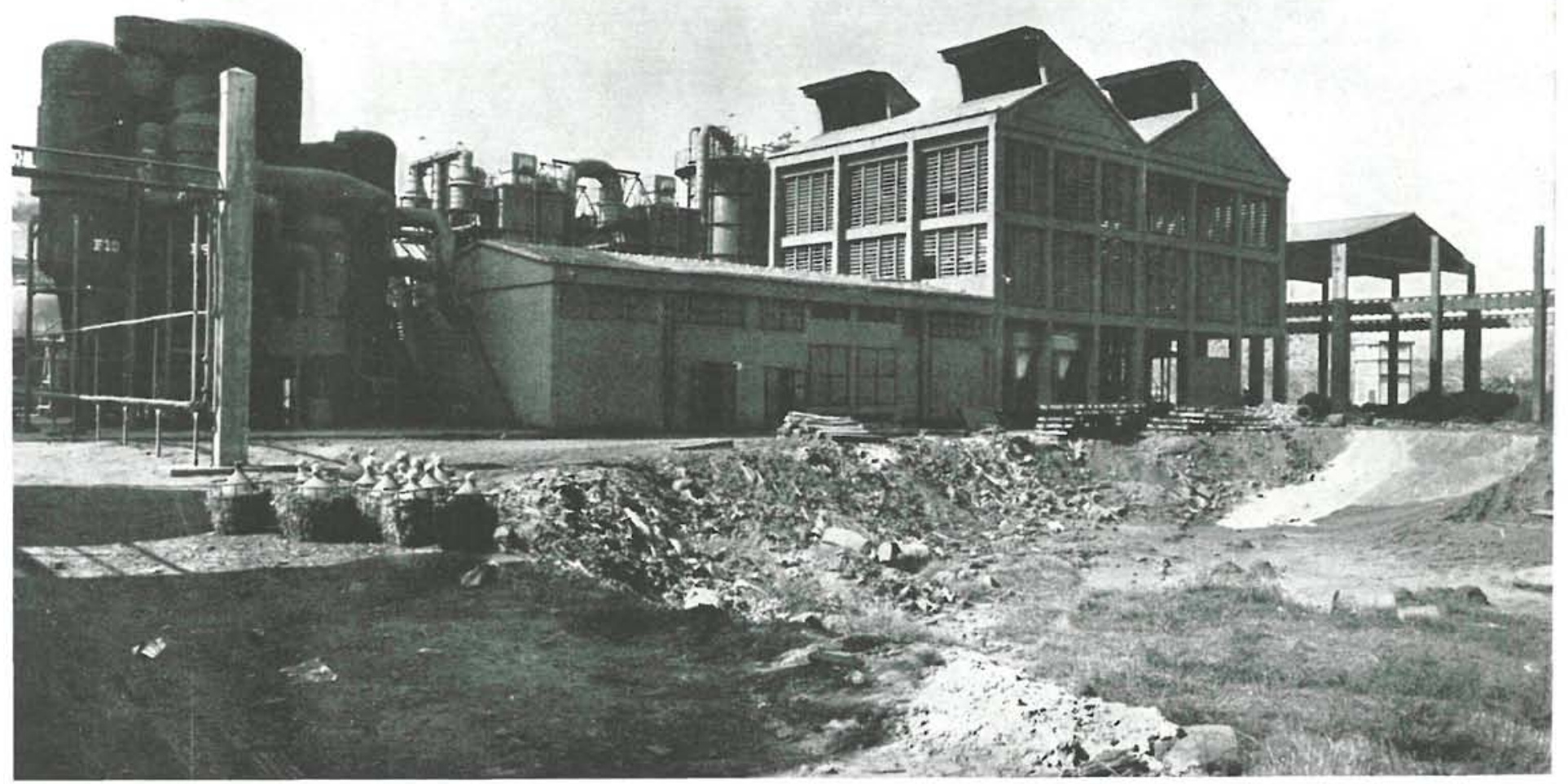

23

instalación de óleum

En esta nave no todos los entramados terminan en cerchas triangulares, pues en algunas el pilar intermedio sube hasta cumbrera.

También disponemos cerchas en la cubierta de dientes de sierra del taller que se organizó al modo clásico, son cerchas triangulares de $7,50 \mathrm{~m}$ de luz apoyadas en pórticos longitudinales, con vanos de $10 \mathrm{~m}$ (fig: 24). Las cerchas se premoldearon como ya hemos indicado.

\section{Construcciones especiales}

Como estructuras especiales tenemos las marquesinas en las puertas del almacén de sulfato y los cobertizos para protección de coches y de productos elaborados en los muelles del servicio ferroviario. Son láminas cilíndricas, de directriz circular, con espesor variable de $6 \mathrm{~cm}$ en clave a $10 \mathrm{~cm}$ en arranques, reforzados por una retícula de nervios en los bordes, en las líneas de apoyo y en las aristas comunes. La luz transversal de las láminas es de $4 \mathrm{~m}$ y el voladizo de la marquesina de sulfato, $6 \mathrm{~m}$. En el cobertizo de protección de vehículos, son dobles voladizos con tramo central de $3 \mathrm{~m}$ (fig. 26).

\section{Taller mecánico.}

Taller del catalizador.
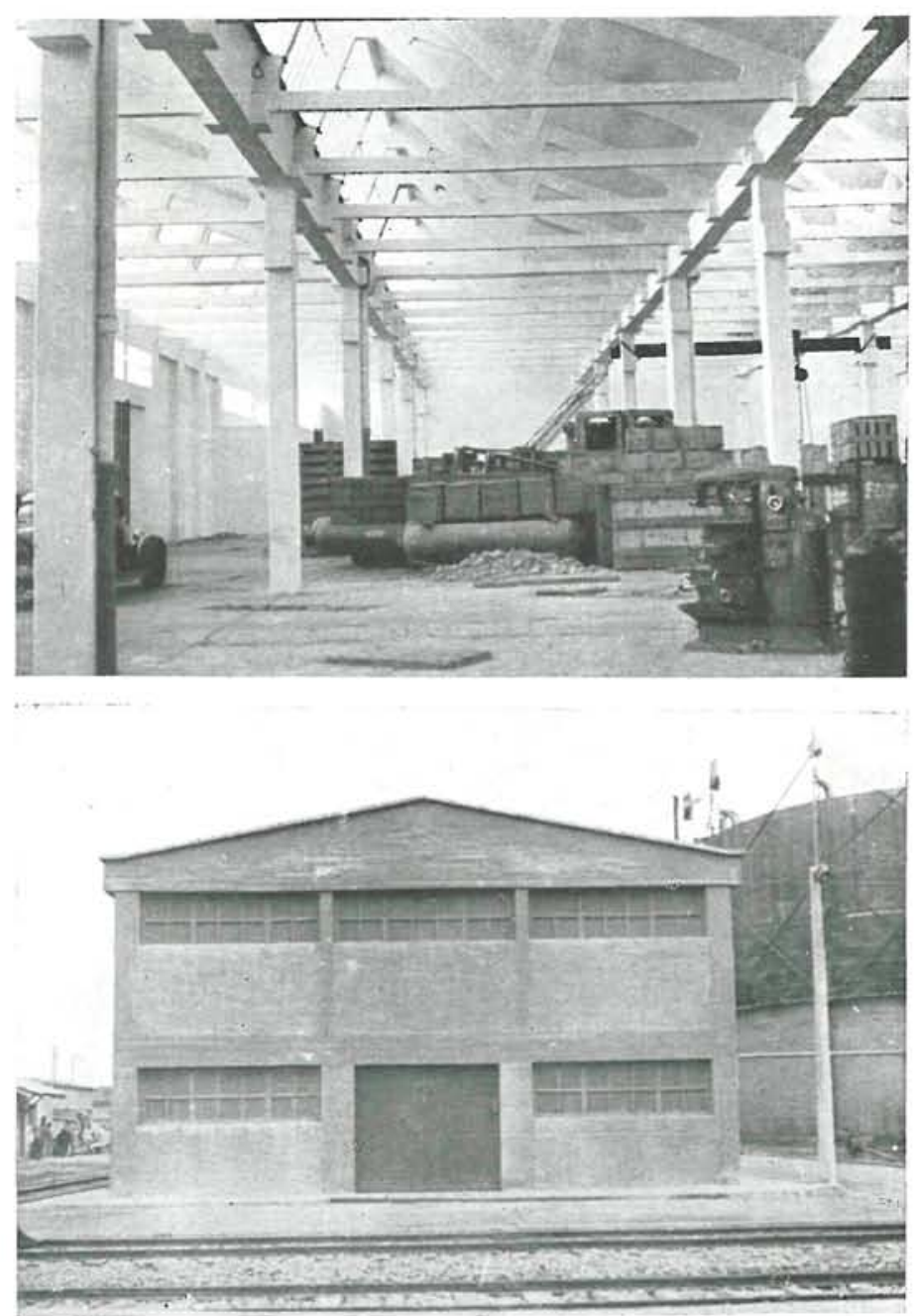


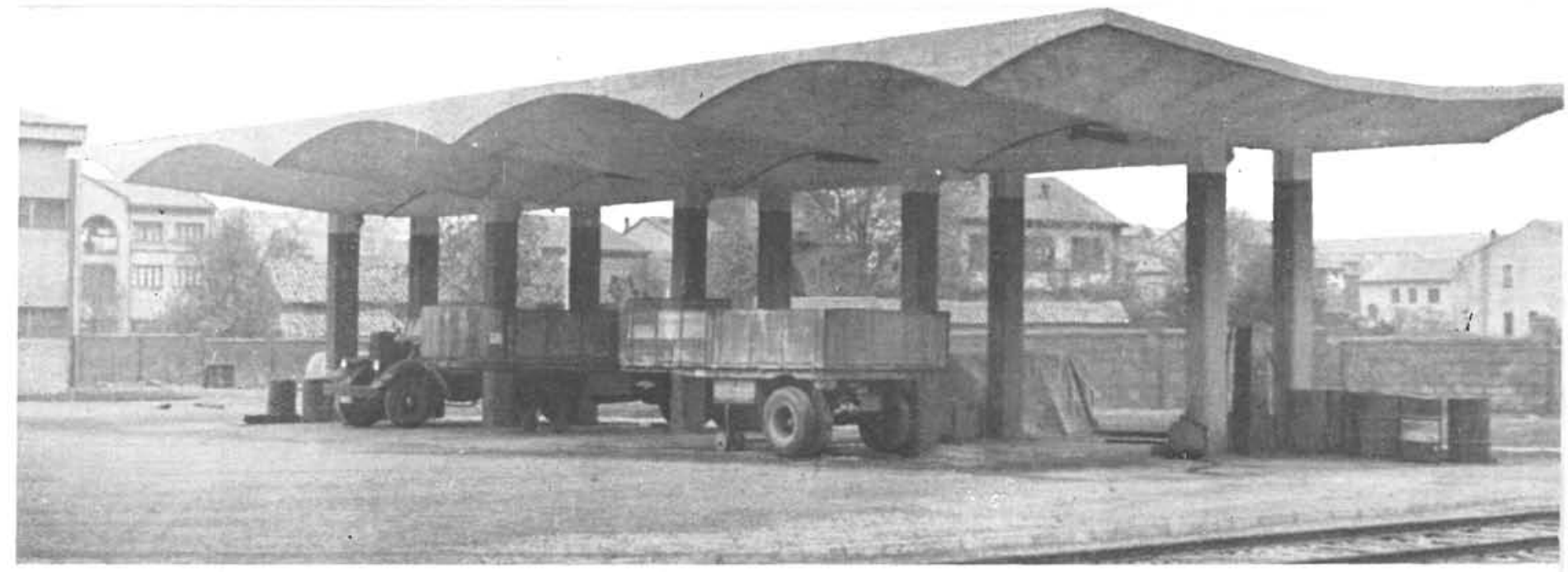

Cobertizo de vehículos.

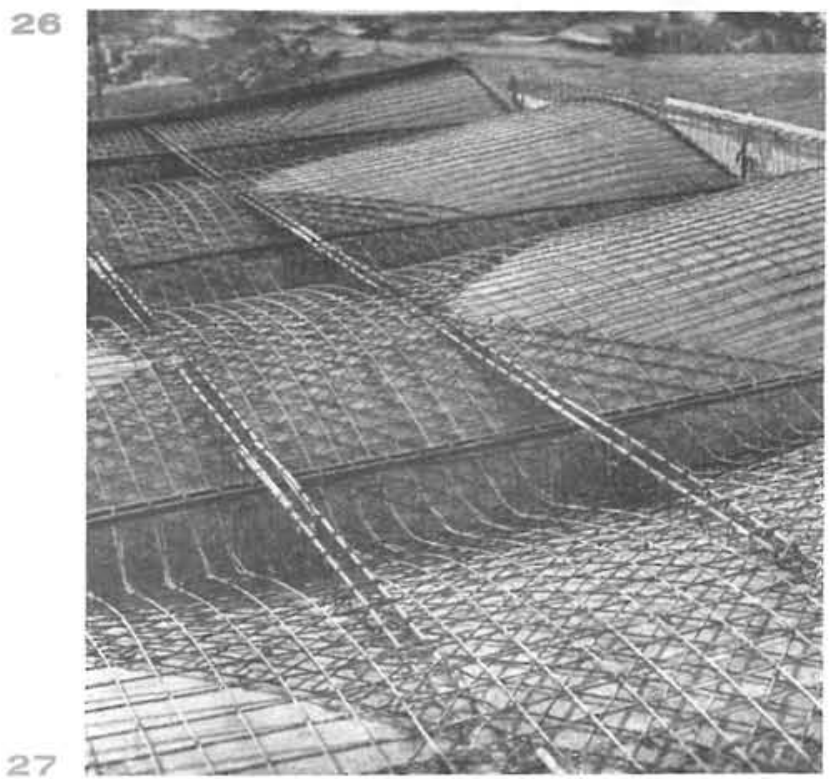

\section{construcciones especiales}

Las instalaciones de clarificación de agua constan de un gran estanque circular, de $22 \mathrm{~m}$ de diámetro, con paredes y fondo de hormigón armado y las casetas de bombas en las que se ha adoptado el tipo de edificación de naves pequeñas.

El soporte de los depósitos cilíndricos de almacenamiento de ácido nítrico da lugar a una estructura muy especial, arborescente con ramificaciones a distintas alturas, volando desde un pórtico central (figuras 28 y 29 ).

Las cubas y cimentaciones de los gasómetros son de hormigón armado, con losa circular y muro anular apoyados sobre terreno firme, habiéndose estudiado el programa de juntas de construcción para aminorar los efectos de la retracción de fraguado. También son de hormigón armado las cimentaciones y balsas de las torres de refrigeración.

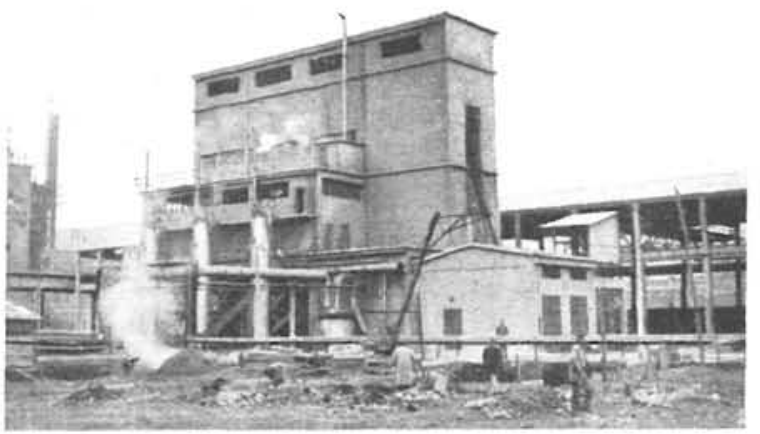

Andén de carga.

Edificio de gasógenos.

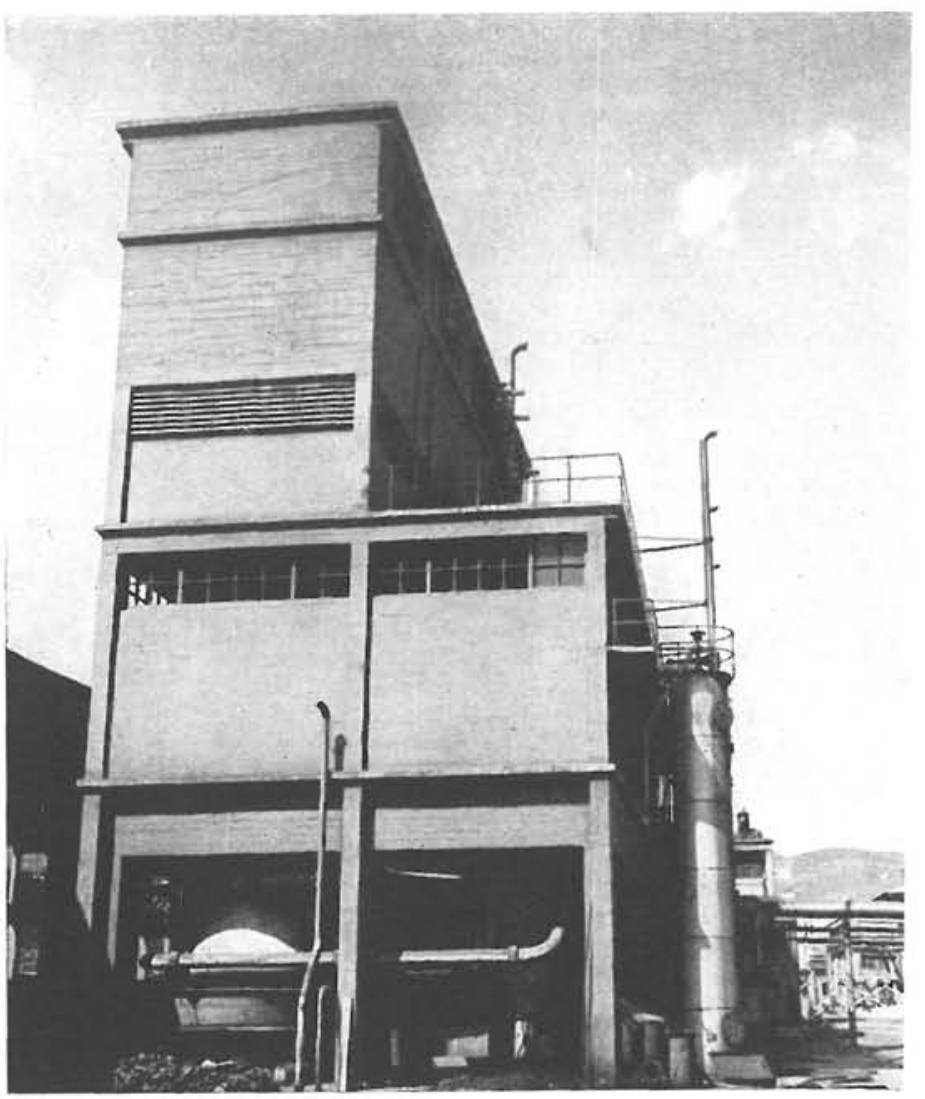


La superestructura de la torre principal de refrigeración se proyectó y realizó por una casa especializada en estas construcciones, emplesndo elementos premoldeados que se solidarizan mediante armadura y hormigonado de elementos kin situm.

La instalación de desgasado, que se realiza mediante recipientes metálicos cilíndricos, lleva unas losas circulares de gran diámetro para apoyo de éstos y una cubierta de $9,50 \mathrm{~m}$ luz con vigas de borde, por las que circula un puente grúa exterior para manejo de tapas y emparrillados internos.

Las obras comenzaron en mayo de 1950 y terminaron en octubre de 1954, con un presupuesto aproximado de $45 \mathrm{mi}$ llones de pesetas. En la actualidad se están ampliando los talleres de nitrico, nitrato, sintesis y desgasado.

Como ya hemos indicado, el planeamiento general de la factoría se llevó a cabo por los ingenieros de S. I. N., con los cuales colaboramos para la definición de los distintos edificios.

El Ingeniero Consejero Delegado es don Francisco Bustelo; el Ingeniero Director de la Sociedad, don Cecilio Ruiz Castillejo; el Director de Fábrica, don Luis Menéndez, y el Encargado de las Obras, don José Echánove.

Fotos: M. GARCIA MOYA

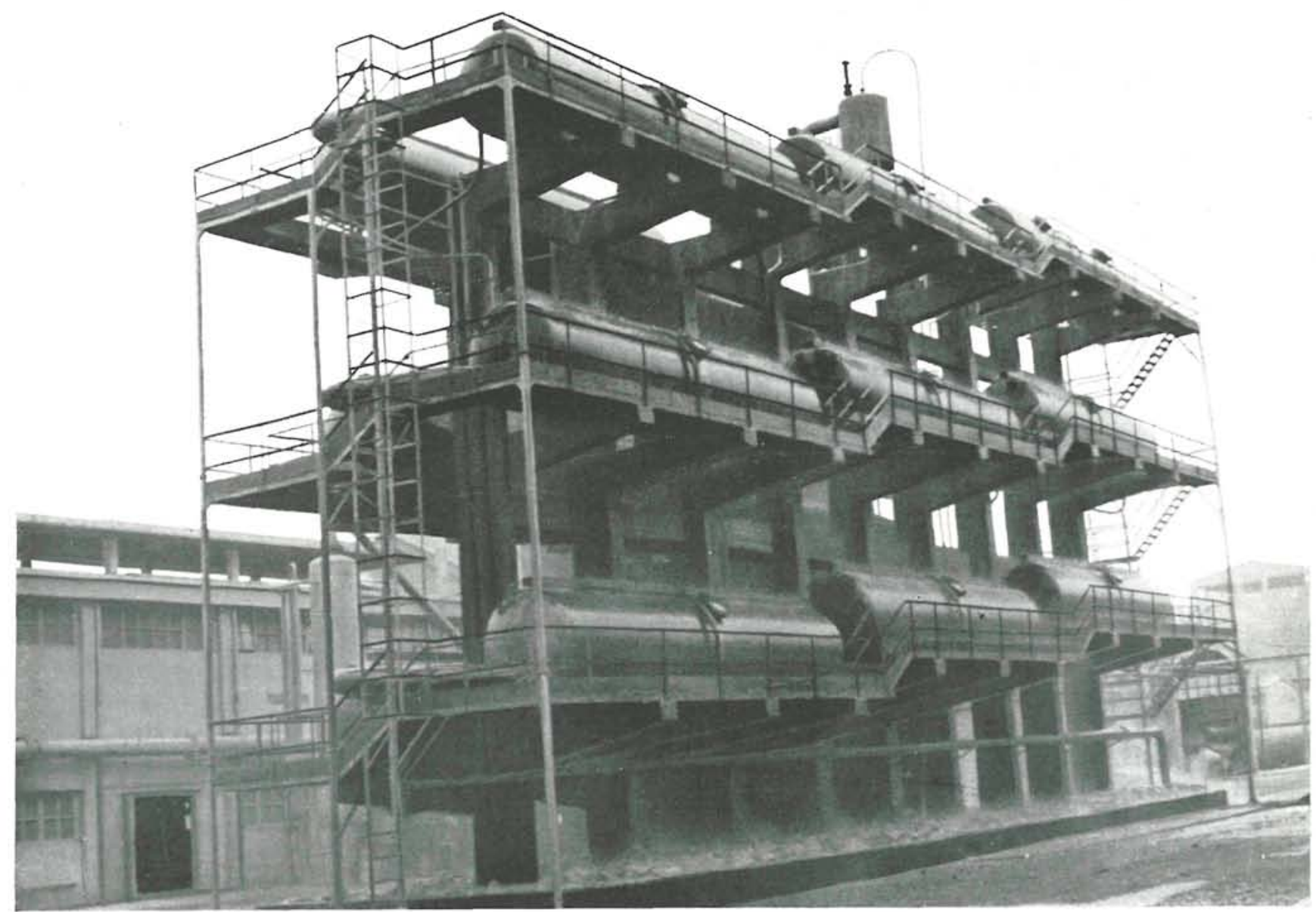

